\title{
The use and misuse of structural equation modeling (SEM) in management research: A review and critique
}

\section{Introduction}

Structural equation models (SEM) with unobservable variables are a dominant research paradigm in the management community today, even though it originates from the psychometric (covariance-based, LISREL) and chemometric research tradition (variance-based, PLS). The establishment of the covariance-based SEM approach can be traced back to the development of the maximum likelihood covariance structure analysis developed by Jöreskog (1966, 1967, 1969, 1970, 1973, 1979) and extended by Wiley (1973). The origins of the PLS approach, developed by Herman Wold, can be traced back to 1963 (Wold 1975, 1982). The first procedures for single- and multi-component models have used least squares (LS), and later Wold (1973) extended his procedure several times under different names: NIPLS (nonlinear iterative partial least square) and NILES (nonlinear iterative least square).

Management measures in self-reporting studies are based almost exclusively (e.g., Diamantopoulos \& Winklhofer 2001; Diamantopoulos et al. 2008) on creating a scale that is assumed reflective and further analysis is dependent on a multitrait-multimethod (MTMM) approach and classical test theory, which implies application of a covariance-based structural equation model (CBSEM). A partial least square (PLS) approach, which was introduced in management literature by Fornell and Bookstein (1982), is another statistical instrument; but so far this approach has not had a wider application in management literature and research practice. The use of PLS for index construction purposes is an interesting area for further research (Diamantopoulos \& Winklhofer 2001; Wetzels et al. 2009) and with new theoretical insights and software developments it is expected that this approach will have wider acceptance and application in the management community.
After reading and reviewing a great number of studies (articles, books, studies, etc.) that apply SEM, as well as analyzing a great number of academic articles (e.g., Diamantopoulos et al. 2008; Finn \& Kayande 2005; Tomarken \& Waller 2005), it has become obvious that many researchers apply this statistical procedure without a comprehensive understanding of its basic foundations and principles. Researchers often fail in application and understanding of (i) conceptual background of the research problem under study, which should be grounded in theory and applied in management; (ii) indicator - construct misspecification design (e.g., Chin 1998; Jarvis et al. 2003; MacKenzie 2001; MacKenzie et al. 2005); (iii) an inappropriate use of the necessary measurement steps, which is especially evident in the application of CBSEM (indices reporting, competing models, parsimonious fit, etc.) and (iv) an inaccurate reporting of the sample size and population under study (cf. Baumgartner \& Homburg 1996).

This is the first study that thoroughly analyzes, reviews and presents two streams using common methodological background. There are examples in the literature that analyze two streams (e.g. Chin 1998; Henseler et al. 2009; Wetzels et al. 2009; Hair et al. 2010; cf. Anderson \& Gerbing 1988), but previous studies take a partial view, analyzing one stream and focusing on the differences and advantages between the two streams. Fornell and Bookstein (1982) have demonstrated in their empirical study many advantages of PLS over LISREL modeling, especially underlying the differences in measurement model specification, in which reflective constructs are associated with LISREL (CBSEM), whereas formative and mixed constructs are associated with PLS (VBSEM). From the present perspective, the study of Fornell and Bookstein makes a great historical contribution because it was the first study that introduced and analyzed the two streams in management research. 
Unfortunately, management theory and practice remained almost exclusively focused on the CBSEM application. Their study has somewhat limited theoretical contribution because they focused only on differences in the measurement model specification between the two streams. We focus on the correct model specification with respect to the theoretical framework, which is a crucial aspect of the model choice in SEM. Our intention is to extend the conceptual knowledge that remained unexplored and unutilized. Our paper is as minimally technical as possible, because our intention is not to develop new research avenues at this point, but to address possible theory enhancements and gaps in extant management research practice.

The purpose of this article is two-fold: (i) to question the current research myopia in management, because application of the latent construct modeling almost blindly adheres only a covariance-based research stream; and (ii) to improve the conceptual knowledge by comparing the most important procedures and elements in the structural equation modeling (SEM) study, using different theoretical criteria. We present the covariance-based (CBSEM) and variance-based (VBSEM) structural equation modeling streams.

The manuscript is organized into several sections. First, we discuss a general approach to structural equation modeling and its applicability in management research. Second, we discuss the two SEM streams in detail, depicted in Table 1, and followed by an analysis of topics such as theory, model specification, sample and goodness-of-fit. The remaining part of the paper is devoted to conclusions and some open questions in management research practice that remain under-investigated and unutilized.

\section{Covariance-based and variance-based structural equation modeling}

Structural models in management are statistical specifications and estimations of data and economic and/or management theories of consumer or firm behavior (cf. Chintagunta et al. 2006). Structural modeling tends to explain optimal behavior of agents and to predict their future behavior and performances. By behavior of agents, we mean consumer utility, employee performances, profit maximizing and organizational performances by firms, etc. (cf. Chintagunta et al. 2006). SEM is a statistical methodology that undertakes a multivariate analysis of multi-causal relationships among different, independent phenomena grounded in reality. This technique enables the researcher to assess and interpret complex interrelated dependence relationships as well as to include the measurement error on the structural coefficients (Hair et al. 2010, MacKenzie 2001). Byrne (1998) has advocated that structural equation modeling has two statistical pivots: (i) the causal processes are represented by a series of structural relations; and (ii) these equations can be modeled in order to conceptualize the theory under study. SEM can be understood as theoretical empiricism because it integrates theory with method and observations (Bagozzi 1994). Hair et al. (2010, p. 616) have advocated that SEM examines "the structure of interrelationships expressed in a series of equations". These interrelationships depict all of the causality among constructs, the exogenous as well as endogenous variables, which are used in the analysis (Hair et al. 2010).

Two SEM streams have been recognized in a modern management research practice. The first one is the "classical" SEM approach - also known by different names including covariance structure analysis and latent variable analysis - which utilizes software such as LISREL or AMOS (Hair et al. 2010; Henseler et al. 2009). We will call this stream covariance-based SEM (CBSEM) in this manuscript. For most researchers in marketing and business research, CBSEM "is tautologically synonymous with the term SEM" (Chin 1998, p. 295). Another stream is known in the literature as partial least squares (PLS) or component-based SEM (e.g., Henseler et al. 2009; McDonald 1996; Tenenhaus 2008). This stream is based on application of least squares using the PLS algorithm with regressionbased methods or generalized structured component analysis (GSCA), which is a fully informational method that optimizes a global criterion (Tenenhaus 2008). This stream will be named the variance-based SEM (VBSEM) in this text.

The rationale behind this notation is grounded on the following three characteristics: 
Basic specification of the structural models is similar, although approaches differ in terms of their model development procedure, model specification, theoretical background, estimation and interpretation (cf. Hair et al. 2010).

VBSEM intends to explain variance, i.e. prediction of the construct relationships (Fornell \& Bookstein 1982; Hair et al. 2010; Hair et al. 2012); CBSEM is based on the covariance matrices; i.e. this approach tends to explain the relationships between indicators and constructs, and to confirm the theoretical rationale that was specified by a model.

Model parameters differ in two streams. The variance-based SEM is working with component weights that maximize variance, whereas the covariance-based SEM is based on factors that tend to explain covariance in the model (cf. Fornell \& Bookstein 1982).

We present Table 1 below; in the remainder of this section, the two streams will be described in detail, using topics such as theory, model specification, sample and goodness-of-fit. Interested readers can use Table 1 as a framework and guide throughout the manuscript.

\section{---- TAKE IN TABLE 1 ----}

\subsection{Theory}

Academic research is grounded in theory, which should be confirmed or rejected, or may require further investigation and development. Hair et al. (2010, p. 620) have argued, "a model should not be developed without some underlying theory", and this process includes measurement and underlying theory. Without proper measurement theory, the researcher cannot develop adequate measures and procedures to estimate the proposed model. Furthermore, the researcher cannot provide proper interpretation of the hypothesized model, there are no new theoretical insights and overall theoretical contribution is dubious without underlying theory (cf. Bagozzi \& Phillips 1982). However, there is an important difference in theory background between CBSEM and VBSEM. CBSEM is considered a confirmatory method that is guided by theory, rather than by empirical results, because it tends to replicate the existing covariation among measures (Fornell \& Bookstein 1982; Hair et al. 2010; Reinartz et al. 2009; cf. Anderson \& Gerbing 1988; Diamantopoulos \& Siguaw 2006; Wetzels et al. 2009), analyzing how theory fits with observations and reality. CBSEM is strictly theory driven, because of the exact construct specification in measurement and structural model as well as necessary modification of the models during the estimation procedure (Hair et al. 2010); "the chi square statistic of fit in LISREL is identical for all possible unobservables satisfying the same structure of loadings, a priori knowledge is necessary" (Fornell \& Bookstein 1982, p. 449).

VBSEM is also based on some theoretical foundations, but its goal is to predict the behavior of relationships among constructs and to explore the underlying theoretical concept. From a statistical point of view, VBSEM reports parameter estimates that tend to maximize explained variance, similarly to OLS regression procedure (Fornell \& Bookstein 1982; Anderson \& Gerbing 1988; Diamantopoulos \& Siguaw 2006; Hair et al. 2010; Hair et al. 2012; cf. Wetzels et al. 2009; Reinartz et al. 2009). Therefore, VBSEM is based on theory, but is data driven in order to be predictive and to provide knowledge and new theoretical rationale about the researched phenomenon. According to Jöreskog and Wold (1982), CBSEM is theory oriented and supports the confirmatory approach in the analysis, while VBSEM is primarily intended for predictive analysis in cases of high complexity and small amounts of information.

There is one important distinction regarding the research orientation between the two streams. Residual covariances in CBSEM are minimized in order to achieve parameter accuracy, however for VBSEM, residual variances "are minimized to enhance optimal predictive power" (Fornell \& Bookstein 1982, p. 443; cf. Bagozzi 1994; Chin 1998; Yuan et al. 2008). In other words, the researcher tends to confirm theoretical assumptions and accuracy of parameters in CBSEM; in contrast, the predictive power of the hypothesized model is the main concern in VBSEM. 


\subsection{Specification of the measurement model}

The vast majority of management research includes self-reported studies of consumer behavior, attitudes and/or opinions of managers and employees, which express the proxy for different behavioral and organizational relationships in business reality. A researcher develops a model that is a representation of different phenomena connected with causal relationships in the real world. In order to provide a theoretical explanation of these behavioral and/or organizational relationships, the researcher has to develop complex research instruments that will empirically describe theoretical assumptions about researched phenomenon. This process is named the measurement model specification (Fornell \& Bookstein 1982; Hair et al. 2010; Rossiter 2002).

A measure is an observed score obtained via interviews, self-reported studies, observations, etc. (Edwards \& Bagozzi 2000; Howell et al. 2007). It is a quantified record that represents an empirical analogy to a construct. In other words, a measure is quantification of the material entity. A construct in measurement practice represents a conceptual entity that describes manifest and/or latent phenomenon as well as their interrelationships, outcomes and performances. Constructs themselves are not real (or tangible) in an objective manner, even though they refer to real-life phenomena (Nunnally \& Bernstein 1994). In other words, the relationship between a measure and a construct represents the relationship between a measure and the phenomenon, in which the construct is a proxy for the phenomena that describe reality (cf. Edwards \& Bagozzi 2000). Throughout this paper, we use the terms "measure" and "indicator" interchangeably to refer to a multiitem operationalization of a construct, whether it is reflective or formative. The terms "scale" and "index" should be used to distinguish between reflective and formative items respectively (Diamantopoulos \& Siguaw 2006).

Academic discussions about the relationships between measures and constructs are usually based on examination of the causality among them. The causality of the reflective construct is directed from the latent construct to the indicators, with the underlying hypothesis that the construct causes changes in the indicators (Fornell \& Bookstein 1982;
Edwards \& Bagozzi 2000; Jarvis et al. 2003). Discussions of formative measures indicate that a latent variable is measured using one or several of its causes (indicators), which determine the meaning of that construct (e.g., Blalock 1964; Edwards \& Bagozzi 2000; Jarvis et al. 2003). Between the reflective and formative constructs exists an important theoretical and empirical difference, but many researchers do not pay appropriate attention to this issue and mistakenly specify the wrong measurement model. According to Jarvis et al. (2003), approximately $30 \%$ of the latent constructs published in the top management journals were incorrectly specified. The model ramification included incorrect specification of the reflective indicators when they should have been formative indicators, at not only the first-order construct level but also the relationships between higher-order constructs (Jarvis et al. 2003). Using the Monte Carlo simulation, they have demonstrated that the misspecification of indicators can cause biased estimates and misleading conclusions about the hypothesized models (cf. Yuan et al. 2008). The source of bias is mistakenly specified due to the direction of causality between the measures and latent constructs, and/or the application of an inappropriate item purification procedure (Diamantopoulos et al. 2008). The detailed descriptions and applications of the reflective and formative constructs are presented in the following subsection.

The latent variables in CBSEM are viewed as common factors, whereas in VBSEM they are considered as components or weighted sums of manifest variables. This implies that latent constructs in the VBSEM approach are determinate, whereas in the CBSEM approach they are indeterminate (Chin 1998; cf. Fornell \& Bookstein 1982). The consequence is the specification of model parameters as factor means in CBSEM, whereas in VBSEM they are specified as component weights (cf. Reinartz et al. 2009). Factors in the CBSEM estimates explain covariance, whereas component weights maximize variance because they represent a linear combination of their indicators in the latent construct (Fornell \& Bookstein 1982). Several researchers have examined the relationships between latent and manifest variables (e.g., Bagozzi 2007; Howell et al. 2007). 
They have suggested that the meaning of epistemic relationships between the variables should be established before its inclusion and application within a nomological network of latent and manifest variables.

The researcher can use single and multiple measures to estimate the hypothesized constructs. Researchers usually use multiple measures because (i) most constructs can be measured only with an error term; (ii) a single measure cannot adequately capture the essence of the management phenomena (cf. Curtis \& Jackson 1962); (iii) it is necessary to prove that the method of measurement is correct (Nunnally \& Bernstein 1994; MacKenzie et al. 2005); and (iv) it is necessary to use a minimum of three indicators per construct in order to be able to identify a model in the CBSEM set-up (cf. Anderson \& Gerbing 1988; Baumgartner \& Homburg 1996). When multiple measures are developed, the researcher has to estimate the model that accurately, validly and reliably represents the relationship between indicators and latent constructs in the structural model. Research bias may arise if the researcher uses very few indices (three or less), or fails to use a large number of indicators for each latent construct (cf. Chin 1998; Peter 1979); so-called "consistency at large". In the VBSEM technique, consistency at large means that parameters of the latent variable model and the number of indicators are infinite (Wold 1980; McDonald 1996; cf. Haenlein \& Kaplan 2004; Reinartz et al. 2009).

The structural constructs (i.e., multidimensional constructs, hierarchical constructs; cf. Fornell \& Bookstein 1982; McDonald 1996; Wetzels et al. 2009; Bagozzi 1994; Chintagunta et al. 2006) represent multilevel inter-relationships among the constructs that involve several exogenous and endogenous interconnections and include more than one dimension. The researcher should distinguish higher-order models from a model that employs unidimensional constructs that are characterized by a single dimension among the constructs. The literature (cf. Fornell \& Bookstein 1982; Chin 1998; Diamantopoulos \& Winklhofer 2001; MacKenzie et al. 2005; Wetzels et al. 2009, etc.) recognize three types of structural constructs: the common latent construct model with reflective indicators, the composite latent construct model with formative indicators, and the mixed structural model.

\subsubsection{Types of latent constructs}

Common topics and criteria for the distinction between reflective and formative indicators are presented in Table 2. These topics are grouped according to two criteria: i) the construct-indicator relationship; and ii) measurement. The constructindicator relationship topic is discussed via employing criteria such as direction of causality, theoretical framework, definition of the latent construct, common antecedents and consequences, internal consistency, validity of constructs and indicator omission consequences. The measurement topic is discussed by analyzing the issue of measurement error, interchangeability, multicollinearity and a nomological net of indicators.

\section{---- TAKE IN TABLE 2 ----}

Application of the classical test theory "assumes that the variance in scores on a measure of a latent construct is a function of the true score plus error" (MacKenzie et al. 2005, p. 710; Podsakoff et al. 2003), as we presented in equations 1 and 2 , in Appendix A. The rationale behind the reflective indicators is that they all measure the same underlying phenomenon (Chin 1998) and they should account for observed variances and covariances (Fornell \& Bookstein 1982; cf. Edwards 2001) in the measurement model. The meaning of causality has direction from the construct to the measures with underlying assumptions that each measure is imperfect (MacKenzie et al. 2005), i.e., that has the error term which can be estimated at the indicator level.

Formative indicators were introduced for the first time by Curtis and Jackson (1962) and extended by Blalock (1964). This type of model specification assumes that the indicators have an influence on (or that they cause) a latent construct. In other words, the indicators as a group "jointly determine the conceptual and empirical meaning of the construct" (Jarvis et al. 2003, p. 201; cf. Edwards \& Bagozzi 2000). The type B model specification would give better explanatory power, in comparison to the type A model specification, if the goal is the explanation 
of unobserved variance in the constructs (Fornell \& Bookstein 1982; cf. McDonald 1996). Application of the formative indicators in the CBSEM environment is limited by necessary additional identification requirements. A model is identified if model parameters have only one set of values that generate the covariance matrix (Gatignon 2003). In order to resolve the problem of indeterminacy that is related to the construct-level error term (MacKenzie et al. 2005), the formative-indicator construct must be associated with unrelated reflective constructs. This can be achieved if the formative construct emits paths to i) at least two unrelated reflective indicators; ii) at least two unrelated reflective constructs; and iii) one reflective indicator that is associated with a formative construct and one reflective construct (MacKenzie et al. 2005; cf. Fornell \& Bookstein 1982; Diamantopoulos \& Winklhofer 2001; Diamantopoulos et al. 2008; Edwards \& Bagozzi 2000; Howell et al. 2007; Bagozzi 2007; Wilcox et al. 2008).

From an empirical point of view, the latent construct captures (i) the common variance among indicators in the type A model specification; and (ii) the total variance among its indicators in the type B model specification, covering the whole conceptual domain as an entity (cf. Cenfetelli \& Bassellier 2009; MacKenzie et al. 2005). Reflective indicators are expected to be interchangeable and have a common theme. Interchangeability, in the reflective context, means that omission of an indicator will not alter the meaning of the construct. In other words, reflective measures should be unidimensional and they should represent the common theme of the construct (e.g. Howell et al. 2007). Formative indicators are not expected to be interchangeable, because each measure describes a different aspect of the construct's common theme, and dropping an indicator will influence the essence of the latent variable (cf. Bollen \& Lenox 1991; Coltman et al. 2008; Diamantopoulos \& Winklhofer 2001; Diamantopoulos et al. 2008; Jarvis et al. 2003).

Internal consistency is implied within the reflective indicators, because measures must correlate. High correlations among the reflective indicators are necessary, because they represent the same underlying theoretical concept. This means that all of the items are measuring the same phenomenon within the latent construct (MacKenzie et al. 2005). On the contrary, within the formative indicators, internal consistency is not implied because the researcher does not expect high correlations among the measures (cf. Jarvis et al. 2003). Because formative measures are not required to be correlated, validity of construct should not be assessed by internal consistency reliability as with the reflective measures, but with other means such as nomological and/or criterion-related validity (cf. Bollen \& Lenox 1991; Coltman et al. 2008; Diamantopoulos et al. 2008; Jarvis et al. 2003; Bagozzi 2007).

The researcher should ascertain the difference of multicollinearity between the reflective and formative constructs. In the reflective-indicator case, multicollinearity does not represent a problem for measurement-model parameter estimates, because the model is based on simple regression (cf. Fornell \& Bookstein 1982; Bollen \& Lenox 1991; Diamantopoulos \& Winklhofer 2001; Jarvis et al. 2003) and each indicator is by purpose collinear with other indicators. However, high inter-correlations among the indicators are a serious issue in the formative-indicator case, because it is impossible to identify the distinct effect of an indicator on the latent variable (cf. Diamantopoulos \& Winklhofer 2001; MacKenzie et al. 2005; Cenfetelli \& Bassellier 2009). The researcher can control for indicator collinearity by assessing the size of the tolerance statistics $\left(1-R_{j}^{2}\right.$ ), where $R_{j}^{2}$ is the coefficient of the determination in predicting variable $X_{j}$ (cf. Cenfetelli \& Bassellier 2009). Inverse expression of the tolerance statistics is the variance inflation factor (VIF), which has different standards of threshold values that range from 3.33 to 10.00 , with lower values being better (e.g. Diamantopoulos \& Siguaw 2006; Hair et al 2010; Cenfetelli \& Bassellier 2009).

The multi-item measures can be created by the scale developed or the index construction. Traditional scale development guidelines will be followed if the researcher conceptualizes the latent construct as giving rise to its indicators, and therefore viewed as reflective indicators to the construct. This procedure is based on the intercorrelations among the items, and focuses on common variance, unidimensionality and internal consistency (e.g. Diamantopoulos \& Siguaw 2006; Anderson \& Gerbing 1982; Churchill 1979, 
Nunnally \& Bernstein 1994). The index development procedure will be applied if the researcher conceptualizes the indicators as defining phenomenon in relation to the latent construct, and therefore will be considered as formative indicators of the construct. Index construction is based on explaining unobserved variance, considers multicollinearity among the indicators and underlines the importance of indicators as predictor rather than predicted variables (e.g. Diamantopoulos \& Siguaw 2006; Bollen 1984; Diamantopoulos \& Winklhofer 2001).

It is possible for a structural model to have one type of latent construct at the first-order (latent construct) level and a different type of latent construct at the second-order level (Fornell \& Bookstein 1982; MacKenzie et al. 2005; Diamantopoulos \& Siguaw 2006; Wetzels et al. 2009). In other words, the researcher can combine different latent constructs to form a hybrid model (Edwards \& Bagozzi 2000; McDonald 1996). Development of this model type depends on the underlying causality between the constructs and indicators, as well as the nature of the theoretical concept. The researcher should model exogenous constructs in the formative mode and all endogenous constructs in the reflective mode, (i) if one intends to explain variance in the unobservable constructs (Fornell \& Bookstein 1982; cf. Wetzels et al. 2009); and (ii) in case of weak theoretical background (Wold 1980). Conducting a VBSEM approach in this model, using a PLS algorithm, is equal to redundancy analysis (Fornell et al. 1988; cf. Chin 1998), because the mean variance in the endogenous construct is predicted by the linear outputs of the exogenous constructs.

\subsubsection{Reliability assessment}

The scale development paradigm was established by Churchill's (1979) work as seen in the management measurement literature. This management measurement paradigm has been investigated and improved by numerous research studies and researchers, with special emphasis on the reliability and validity of survey research indicators and measures (e.g., Peter 1981; Anderson \& Gerbing 1982; Fornell \& Bookstein 1982; Churchill \& Peter 1984; Finn \& Kayande 2004, etc.). Any quantitative research must be based on accuracy and reliability of measurement (Cronbach 1951). A reliability coefficient demonstrates the accuracy of the designed construct (Cronbach 1951; cf. Churchill \& Peter 1984) in which certain collection of items should yield interpretation regarding the construct and its elements.

It is highly likely that no other statistic has been reported more frequently in the literature as a quality indicator of test scores than Cronbach's (1951) alpha coefficient (Sijtsma 2009; Shook et al. 2004). Although Cronbach (1951) did not invent the alpha coefficient, he was the researcher who most successfully demonstrated its properties and presented its practical applications in psychometric studies. The invention of the alpha coefficient should be credited to Kuder and Richardson (1937), who developed it as an approximation for the coefficient of equivalence, and named it $\mathrm{r}_{\mathrm{tt}(K R 20)}$; and Hoyt (1941), who developed a method of reliability based on dichotomous items, for binary cases where items are scored 0 and 1 (cf. Cronbach 1951; Sijtsma 2009). Guttman (1945) and Jackson and Ferguson (1941) also contributed to the development of Cronbach's version of the alpha coefficient, by further development of data derivations for Kuder and Richardson's $r_{t t(K R 20)}$ coefficient, using the same assumptions but without stringent expectations on the estimation patterns. The symbol $\alpha$ was introduced by Cronbach (1951, p. 299) “... as a convenience. 'Kuder-Richardson Formula 20' is an awkward handle for a tool that we expect to become increasingly prominent in the test literature". Cronbach's $\alpha$ measures how well a set of items measures a single unidimensional construct. In other words, Cronbach's $\alpha$ is not a statistical test, but a coefficient of an item's reliability and/or consistency. The most commonly accepted formula for assessing the reliability of a multi-item scale could be represented by:

$$
\alpha=\left(\frac{N}{N-1}\right)\left(1-\frac{\sum_{i=1}^{N} \sigma_{i}^{2}}{\sigma_{t}^{2}}\right)
$$

where $N$ represents the item numbers, $\sigma_{i}^{2}$ is the variance of the item $i$ and $\sigma_{t}^{2}$ represents the total variance of the scale (cf. Cronbach 1951; Peter 1979; Gatignon 2003). In the standardized form, alpha can 
be calculated as a function of the total items correlations and the inter-item correlations:

$$
\alpha=\frac{N \overline{\mathrm{c}}}{\overline{\mathrm{v}}+(N-1) \bar{c}}
$$

where $N$ is item numbers, $c$-bar is the average item-item covariance and $v$-bar is the average variance (cf. Gerbing \& Anderson 1988). From this formula it is evident that items are measuring the same underlying construct, if the $c$-bar is high. This coefficient refers to the appropriateness of item(s) that measure a single unidimensional construct. The recommended value of the alpha range is from 0.6 to 0.7 (Hair et al. 2010; cf. Churchill 1979), but in academic literature a commonly accepted value is higher than 0.7 for a multi-item construct and 0.8 for a single-item construct. Academic debate on the pales and usefulness of several reliability indicators, among them Cronbach's $\alpha$, is unabated in the psychometric arena, but this debate is practically unknown and unattended in the management community. The composite reliability, based on a coefficient alpha research paradigm, cannot be a unique assessment indicator because it is limited by its research scope (Finn \& Kayande 1997) and is an inferior measure of reliability (Baumgartner \& Homburg 1996). Alpha is a lower bound to the reliability (e.g., Guttman 1945; Jackson \& Agunwamba 1977; Ten Berge \& Sočan 2004; Sijtsma 2009) and is an inferior measure of reliability in most empirical studies (Baumgartner \& Homburg 1996). Alpha is the reliability if variance is zero for all $i$-th $\neq j$-th, which implies essential $\tau$ equivalence among the items, but this limitation is not very common in practice (Ten Berge \& Sočan 2004; Sijtsma 2009).

We shall now discuss several alternatives to the alpha coefficient that are not well-known in practical applications and the management community. The reliability of the test score $\mathrm{X}$ in the population is denoted by $\rho_{\mathrm{xx}}$. It is defined as the product-moment correlation between scores on $\mathrm{X}$ and the scores on parallel test scores X' (Sijtsma 2009). From the psychometric studies, we have a well-known:

$$
0 \leq \rho_{x x}, \leq 1
$$

and

$$
\rho_{\mathrm{xx}}=1-\frac{\sigma_{E}^{2}}{\sigma_{X}^{2}}
$$

where $\sigma_{E}^{2}$ represents variance of the random measurement error and $\sigma_{X}^{2}$ represents variance of the test score. It is evident from equation (8) that the reliability can be estimated if (i) two parallel versions of the test are analyzed; and (ii) the error variance is available (Sijtsma 2009; Gatignon 2003). These conditions are not possible in many practical applications. Several reliability coefficients have been proposed as a better solution for the data from a single test administrator (Guttman 1945; Nunnally \& Bernstein 1994; Sijtsma 2009), such as the GLB and Guttman's $\lambda_{4}$ coefficient.

The greatest lower bound (GLB) represents the largest value of an indicator that is smaller than each of the indicators in a set of constructs. The GLB solution holds by finding the nonnegative matrix $C_{E}$ that is positive semidefinite (PSD):

$$
\mathrm{GLB}=1-\frac{\operatorname{tr}\left(C_{E}\right)}{\operatorname{Var}(X)}
$$

where $C_{E}$ represents the inter-item error covariance matrix. Equation (9) represents the GLB under the limitation that the sum of error variances correlate zero with other indicators (Sijtsma 2009), because it is the greatest reliability that can be obtained using an observable covariance matrix.

Guttman's $\lambda_{4}$ reliability coefficient is based on the split-half lower bounds paradigm. The difference between Guttman's $\lambda_{4}$ and the traditional "corrected" split-half coefficient is that it uses estimation without assumptions of equivalence. The split-half lower bound to reliability, with assumption of experimentally independent parts (Guttman 1945), is defined by

$$
\lambda_{4}=\mathrm{n}\left(1-\frac{\sigma_{i}^{2}+\sigma_{j}^{2}}{\sigma_{t}^{2}}\right)
$$

where $\sigma_{i}^{2}$ and $\sigma_{j}^{2}$ represent the respective variances of the independent parts and $n$ represents the number of parts to be estimated. Guttman (1945) has proved that $\lambda_{4}$ is a better coefficient in comparison to the traditional "corrected" split-half coefficient, and that alpha coefficient, in Guttman (1945) notated as $\lambda_{3}$, is lower bound to $\lambda_{4}$. 
The relationships among different reliability indicators are:

$$
0 \leq \text { alpha }\left(\lambda_{3}\right) \leq \lambda_{4} \leq \mathrm{GLB} \leq \rho_{\mathrm{xx}} \leq 1
$$

This expression is true, because we know from Guttman (1945) that alpha $\left(\lambda_{3}\right) \leq \lambda_{4}$, from Jackson and Agunwamba (1977) that $\lambda_{4} \leq$ GLB, and from Ten Berge and Sočan (2004) that GLB $\leq \rho_{\mathrm{xx}} \leq 1$. The alpha and Guttman's $\lambda$ can be estimated using the SPSS, and the GLB can be calculated by the program MRFA2 (Ten Berge \& Kiers 2003).

From a research point of view the composite reliability, based on Cronbach's so-called alpha indicator, cannot solely be an assessment indicator because it is limited by its scope only on the scaling of person, rather than on the scaling of objects such as firms, advertisements, brands, etc. (e.g., Peter 1979; Finn \& Kayande 1997). The generalizability theory (G-theory) introduced by Cronbach and colleagues (1972) and measured by the coefficient of generalizability includes wider management facets and takes into account many sources of error in a measurement procedure. The G-theory represents a multifaceted application of measurement (Cronbach et al. 1972; Finn \& Kayande 1997) that generalizes over the scaling of persons in the population and focuses on the scaling of objects such as organizations, brands, etc. The measurement in Gtheory is conducted by variation from multiple controllable sources, because random effects and variance elements of the model are associated with multiple sources of variance (Peter 1979; Finn \& Kayande 1997). The coefficient of generalizability is defined by the estimate of the expected value of $\rho^{2}$ (Cronbach et al. 1972):

$$
\mathrm{E} \hat{\rho}^{2}=\frac{\sigma_{\text {universe score }}^{2}}{\sigma_{\text {universe score }}^{2}+\sigma_{\text {relative error }}^{2}}
$$

where $\sigma_{\text {us }}^{2}$ represents the variance component related to an object of measurement, and $\sigma_{\text {re }}^{2}$ represents the sum of variance that affects the scaling of the object of measurement. This measure has no wider application in the management community due to its robust measurement metrics and high cost. There is some evidence in the literature (e.g., Finn \& Kayande 1997) that a piece of such research, with 200 respondents, may cost approximately 10,000 US\$ (as of 1995).
In summary, researchers should be aware that conventional reporting of the alpha coefficient has empirical and conceptual limitations. We recommend that authors should make additional efforts to report Guttman's $\lambda$ (from SPSS, same as alpha) together with the alpha coefficient.

Cohen's $f^{2}$. The researcher can evaluate a VBSEM model by assessing the R-squared values for each endogenous construct. This procedure can be conducted because the case values of the endogenous construct are determined by the weight relations (Chin 1998). The change in R-squares will show the influence of an individual exogenous construct on an endogenous construct. The effect size $f^{2}$ has been used as a reliability measure in the VBSEM applications, but researchers do not address properly the role of effect size effects in the model. It is usual practice to report this effect directly from statistical program (such as SmartPIS), but this is not an automatic function and statistical power of the model must be calculated additionally. This indicator is proposed by Cohen (1988) and can be "calculated as the increase in $\mathrm{R}^{2}$ relative to the proportion of variance of the endogenous latent variable that remains unexplained" (Cohen 1988; 1991; cf. Chin 1998). To estimate the overall effect size of the exogenous construct, the following formula can be used:

$$
f^{2}=\frac{R^{2}{ }_{e x}}{1-R^{2} e x}
$$

Another way to calculate this indicator is with a power analysis program such as GPower 3.1. The researcher can easily estimate effect size $f^{2}$ using partial R-squares (Faul et al. 2009). Cohen (1988; 1991) has suggested that values of $0.02,0.15$ and 0.35 have weak, medium or large effects, respectively.

Composite reliability $\rho_{c}$ indicator. The VBSEM models in reflective mode should apply the composite reliability $\rho_{\mathrm{c}}$ measure or Cronbach's $\alpha$ (and/or Guttman's $\lambda_{4}$ and GLB), as a control for internal consistency. The composite reliability $\rho_{c}$ indicator was developed by Werts, Linn and Jöreskog (1974) and can be interpreted in the same way as Cronbach's $\alpha$ (Chin 1998; Henseler et al. 2009). This procedure applies the normal partial least square 
output, because it standardizes the indicators and latent constructs (Chin 1998).

$$
\rho_{\mathrm{c}}=\frac{\left(\sum \lambda_{\mathrm{ij}}\right)^{2}}{\left(\sum \lambda_{\mathrm{ij}}\right)^{2}+\sum \operatorname{var}\left(\varepsilon_{\mathrm{ij}}\right)}
$$

where $\lambda_{\mathrm{ij}}$ represents the component loading on an indicator by the $j$-th latent construct and $\operatorname{Var}\left(\varepsilon_{\mathrm{ij}}\right)=1-$ $\lambda_{\mathrm{ij}}{ }^{2}$. The $\rho_{\mathrm{c}}$ has more accurate parameter estimates in comparison to Cronbach's $\alpha$, because this indicator does not assume tau equivalency among the constructs. Werts et al. (1974) have argued that the composite reliability $\rho_{\mathrm{c}}$ is more appropriate to apply to VBSEM applications than Cronbach's $\alpha$, because Cronbach's $\alpha$ may produce serious underestimation of the internal consistency of latent constructs. This is the case because Cronbach's $\alpha$ is based on the assumption that all indicators are equally reliable. The partial least square procedure ranks indicators according to their reliability (Henseler et al. 2009) and makes them a more reliable measure in the VBSEM application. The composite reliability $\rho_{\mathrm{c}}$ is only applicable in the latent constructs with reflective measures (Chin 1998).

\section{---- TAKE IN TABLE 3 ----}

\subsubsection{Validity assessment}

The ongoing discussion in the measurement literature (e.g., Rossiter 2002; Diamantopoulos \& Siguaw 2006; Finn \& Kayande 2005) on procedures for the development of scales and indexes to measure constructs in management is beyond the scope of this manuscript. We only want to draw attention at this point to the validity and reliability of applied constructs. Validation represents the process of obtaining the scientific evidence for a suggested interpretation of quantitative results from a questionnaire by the researcher. In research practice, validity is very often assessed together with reliability. This process represents the extent to which a measurement concept obtains consistent estimations. From a statistical point of view, test validity represents the degree of correlation between the model and statistical criterion. The validity procedure has gained greater importance in SEM application than in other statistical instruments, because i) this procedure makes an important distinction between the measurement and the structural model; and ii) this application provides a more stringent test of discriminant validity, construct reliability, etc. (e.g.,Fornell \& Larcker 1981; Gerbing \& Anderson 1988; Jarvis et al. 2003; cf. Peter 1979).

Construct validity is a necessary condition for testing the hypothesized model (Gerbing \& Anderson 1988), because "construct validity pertains to the degree of correspondence between constructs and their measures" (Peter 1981, p. 133; cf. Curtis \& Jackson 1962; Bagozzi \& Phillips 1982). In other words, construct validity represents the extent to which operationalizations of a latent construct measures the underlying theory. Evidence of construct validity represents empirical support for the theoretical interpretation of the constructs. The researcher must assess the construct validity of the model, without which one cannot estimate and correct for the influences of measurement errors that may deteriorate the estimates of theory testing (Bagozzi \& Phillips 1982; Bagozzi et al. 1991). However, researchers must be aware that construct validity is applicable only with reflective constructs. The fidelity of formative measures in CBSEM, except in some limited cases such as concurrent or predictive validity (Bagozzi 2007), is hard to assess and difficult to justify in terms of the conceptual meaning of a model.

Discriminant validity represents the distinctive difference among the constructs. In other words, discriminant validity shows the degree to which the indicators for each of the constructs are different from each other (cf. Churchill 1979; Bagozzi \& Phillips 1982). The researcher can assess the discriminant validity by examining the level of correlations among the measures of independent constructs. A low intra-construct correlation is a sign of discriminant validity. The average variance extracted (AVE) for each construct should be greater than squared correlations among the measures of a construct in order to ensure the discriminant validity (Fornell \& Larcker 1981).

Nomological aspects of validation include connecting the index to other constructs with which it should be connected, for instance, antecedents and/or consequences (Diamantopoulos \& Winklhofer 2001; Jarvis et al. 2003; cf. Gerbing \& Anderson 1988). Nomological validity can be assessed by estimating the latent construct and testing whether correlations 
between antecedents and consequences are significantly higher than zero (MacKenzie et al. 2005). This validation is especially important when certain indicators are eliminated from the constructs and the researcher has to establish whether new constructs behave in an expected way. In other words, the nomological net of indicators should not differ in the reflective mode and may differ in the formative mode (e.g., Bollen \& Lenox 1991; Jarvis et al. 2003).

\subsubsection{Type of study}

The management studies that investigate organizational constructs, such as market/consumer orientation, sales force, etc., and drivers of success are by their nature theory predictive rather than theory confirmatory studies. These constructs are determined by a combination of factors that cause specific phenomenon and their indicators should be created in a formative mode (Fornell \& Bookstein 1982; Chin 1998). This implies that this type of study is better with VBSEM, but decisions about the approach should be made after careful examination of all elements that influence the two streams. However, behavioral studies that are based on psychometric analysis of factors such as attitudes, consumer intentions, etc., are seen as underlying factors that confirm a specific theory. They "give rise to something that is observed" (Fornell \& Bookstein 1982, p. 442) and should be created in a reflective mode. The researcher should start the conceptual examination from the CBSEM point of view.

\subsubsection{The structure of unobservables}

The structure of unobservables in the SEM constructs is a primary difference between CBSEM and VBSEM, because CBSEM specifies the residual structure and VBSEM "specifies the estimates of the unobservables explicitly" (Fornell \& Bookstein 1982, p. 449). In other words, the underlying constructs are modeled as indeterminate in CBSEM and determinate in VBSEM. Indeterminacy can create difficulties for confirmatory studies because indeterminate factors have improper loadings (Fornell \& Bookstein 1982) and assignment of surplus variance to the unobservable may lead to biased measurement results. The structure of unobservables in the VBSEM approach is determinate. The PLS procedure tries to minimize the variance of all dependent variables, because parameter estimates are obtained by minimizing the residual variance in latent and observed variables (Chin 1998). Bollen (1989b) has noted that the determinate nature of the VBSEM approach avoids parameter identification problems, which can occur in the CBSEM approach.

\subsubsection{Input data}

The CBSEM approach is based on a covariance or correlation input matrix as input data. The literature (e.g., Baumgartner \& Homburg 1996) has suggested that researchers in most cases apply maximum likelihood (ML), unweighted least squares (ULS) and generalized least squares (GLS) that are scale invariant and estimate scale free. This implies that a choice between covariance and correlation input matrix has no effect on overall goodness-of-fit and parameter estimates, but standard errors can be biased if the correlation input matrix has been used (Baumgartner \& Homburg 1996). Another issue is the application of correlation input matrices as if they were covariance matrices, because estimated standard errors are biased (Tomarken \& Waller 2005). A general suggestion for researchers is to use a covariance input matrix as a preferred matrix type (e.g., Jöreskog \& Sörbom 1996). As input data, the VBSEM approach uses individual-level raw data. The VBSEM parameter estimation is based on a least square algorithm.

\subsection{Sample}

A sample should represent a relevant part of reality. Identification and determination of the proper reality is a crucial step in the research set-up. There are many research studies in management that operate without a clear population of objects and an indication of the sample size under study. For instance, a researcher studies the problem of innovation in management. He/she conducts (or attempts to conduct) interviews with a great number of managers (>1000) from different industries, different management levels, different positions in companies, and different working and life experience and expectations. The first issue is that of objective reality. What does the researcher study? The great 
population diversification leads to an inconsistent sample and biased estimation about the researched phenomenon, because of very heterogeneous variables (industry, position, experience, etc.). The second issue is sampling. Identifying the $N$-number of respondents to which the researcher can send his/her questionnaire is not the reality he/she wants to investigate. The researcher wants to identify the sample that is a representative part of objective reality. In the self-reported studies, which deal with cross-sectional data, the acceptable threshold level is $15 \%$ (Hair et al. 2010). The researcher should consider the following two questions regarding the appropriateness of the employed sample size and model. Firstly, what is the proper sample size, in comparison to the number of observations, which will represent business reality? Secondly, what is the appropriate number of indicators to be estimated, in comparison with the obtained sample size, in a proposed model (cf. Baumgartner \& Homburg 1996)?

The appropriate sample size of the model differs in two streams. The importance of sample size lies in the fact that it serves as a basis for estimation of the error term and the most important question is how large a sample must be to obtain credible results (Hair et al. 2010). There is no general rule of thumb or formula which can give an exact solution for the necessary number of observations in SEM. The adequate size of a sample in the CBSEM approach depends on several factors (cf. Hair et al. 2010; Marcoulides \& Saunders 2006) such as i) multivariate normality; ii) applied estimation technique (cf. Baumgartner \& Homburg 1996), because there can be applied maximum likelihood estimation (MLE), weighted least squares (WLS), generalized least squares (GLS), asymptotically distribution free (ADF) estimation, etc. (cf. Jöreskog \& Sörbom 1996; Byrne 1998; Baumgartner \& Homburg 1996); iii) model complexity, because more complex models require more observations for the estimation; iv) missing data, because it reduces the original number of cases; v) communality in each construct, i.e. the average variance extracted in a construct. A great number of simulation studies on CBSEM (usually the Monte Carlo simulation) report estimation bias, improper results and nonconvergence problems with respect to sample size (e.g., Henseler et al. 2009) and inadequate indicator loadings (Reinartz et al. 2009). In general, the researcher can apply the necessary sample size rule, bearing in mind the above limitations and suggestions, if the ratio of sample size to free model parameters is at least five observations to one free parameter for the minimum threshold level and ten to one for the optimum threshold level (cf. Baumgartner \& Homburg 1996; Marcoulides \& Saunders 2006; Peter 1979). Baumgartner and Homburg (1996) have shown that the average ratio of sample size to number of parameters estimated in management literature (from 1977-1994) is 6.4 to 1.

The VBSEM approach is more robust and less sensitive to sample size, in comparison to the CBSEM approach. For instance, Wold (1989) has successfully conducted a study with 10 observations and 27 latent constructs; Chin and Newsted (1999) have conducted a Monte Carlo simulation study on VBSEM in which they have found that the VBSEM approach can be applied to a sample of 20 observations. In general, the rule of thumb that researchers can use in VBSEM runs as follows (Chin 1998): i) 10 observations multiplied with the construct that has the highest number of indicators; ii) the endogenous construct with the largest number of exogenous constructs, multiplied by ten observations. However, the researcher should be careful when employing the small sample size cases in the VBSEM study, because the PLS technique is not the silver bullet (cf. Marcoulides \& Saunders 2006) for any level of sample size, even though it offers "soft" assumptions on data distribution and sample size.

\subsection{Goodness-of-fit}

\subsubsection{Goodness-of-fit in VBSEM}

A model evaluation procedure in VBSEM is different in comparison to the CBSEM approach. The VBSEM application is based on the partial least squares procedure that has no distributional assumptions, other than predictor specification (Chin 1998). Traditional parametric-based techniques require identical data distribution. Evaluation of the VBSEM models should apply the measures that are prediction oriented rather than confirmatory oriented based on covariance fit (Wold 1980; Chin 1998). 
The researcher has to assess a VBSEM model evaluating the model predictiveness (coefficient of determination, $\mathrm{Q}^{2}$ predictive relevance and average variance extracted - AVE) and the stability of estimates applying the resampling procedures (jackknifing and bootstrapping). Technical discussion is presented in Appendix C.

Assessment of the VBSEM model starts with evaluation of the coefficient of determination $\left(\mathrm{R}^{2}\right)$ for the endogenous construct. The procedure is based on the case values of the endogenous constructs that are determined by the weight relations and interpretation is identical to the classical regression analysis (Chin 1998). For instance, Chin (1998b, p. 337) has advocated that the R-squared values $0.63,0.33$ and 0.19 , in the baseline model example, show substantial, moderate and weak levels of determination, respectively.

The second element of the VBSEM assessment is that of predictive relevance, measured by the Qsquared indicator. The $\mathrm{Q}^{2}$ predictive relevance indicator is based on the predictive sample reuse technique originally developed by Stone (1974) and Geisser $(1975 ; 1974)$. The VBSEM adaptation of this approach is based on a blindfolding procedure that excludes a part of the data during parameter estimation and then calculates the excluded part using the estimated parameters.

The average variance extracted (AVE) represents the value of variance captured by the construct from its indicators relative to the value of variance due to measurement errors in that construct. This measure has been developed by Fornell and Larcker (1981). The AVE is only applicable for type A models; i.e. models with reflective indicators, just as in the case of the composite reliability measure (Chin 1998). The AVE should be higher than 0.50 , i.e. more than $50 \%$ of variance should be captured by the model.

VBSEM parameter estimates are not efficient as CBSEM parameter estimates and resampling procedures are necessary to obtain estimates of the standard errors (Anderson \& Gerbing 1988). The stability of estimates in the VBSEM model can be examined by resampling procedures such as jackknifing and bootstrapping. Resampling estimates the precision of sample statistics by using the portions of data (jack-knifing) or drawing random replacements from a set of data blocks (bootstrapping) (cf. Efron
1979; 1981). Jack-knifing is an inferential technique used to obtain estimates by developing robust confidence intervals (Chin 1998). This procedure assesses the variability of the sample data using nonparametric assumptions and "parameter estimates are calculated for each instance and the variations in the estimates are analyzed" (Chin 1998, p. 329). Bootstrapping represents a nonparametric statistical method that obtains robust estimates of standard errors and confidence intervals of a population parameter. In other words, the researcher estimates the precision of robust estimates in the VBSEM application. The procedure described in this section is useful for the assessment of the structural VBSEM model, but detailed description and assessment steps of the outer and inner models are beyond the scope of this manuscript.

\subsubsection{Goodness-of-fit in CBSEM}

CBSEM procedure should be conducted by the researcher in three phases. The first phase is the examination of i) estimations of causal relationships; and ii) goodness-of-fit between the hypothesized model and observed data. The second phase involves model modifications in order to obtain the model with better fit or more parsimonious estimations. The third phase is justification that a nested model is superior in comparison to the original one (cf. Anderson \& Gerbing 1982).

In the first phase, the researcher begins by examining the estimated value of individual paths among latent constructs. The statistical significance of individual path coefficients is established by the $t$ values or $z$-values associated with structural coefficients (Schreiber et al. 2006). The second step is examination of the goodness-of-fit between the hypothesized model and observed data. Covariancebased structural equation modeling has no single statistical test or single significant threshold that leads to acceptance or refusal of the model estimations. It is, rather, the opposite - it has developed a great number of goodness-of-fit measures that assess the overall results of the model from different perspectives: overall fit, comparative fit and model parsimony. Measures of absolute fit determine the degree to which the overall model predicts the observed covariance/correlation matrix (Hair et al. 2010). 
There is no rule of thumb for what model fit serves as the threshold in covariance-based structural equation modeling. There are attempts in the literature (e.g., Bentler \& Bonett 1980; Hu \& Bentler 1999; etc.) to obtain "golden rules", "silver metrics" or "rules of thumb" for the assessment of CBSEM. Setting "rules of thumb" is popular among researchers, because an established threshold level allows easy and fast evaluation of the covariancebased models. The traditional cutoff values in practice, for incremental fit measures $\geq 0.90$, have little statistical justification and are mostly based on intuition (Marsh et al. 2004; cf. Baumgartner \& Homburg 1996; Tomarken \& Waller 2005). This issue has also been addressed by $\mathrm{Hu}$ and Bentler (1998, 1999), who have suggested new, more stringent guidelines. According to these guidelines, the goodness-of-fit measures should be evaluated at $\geq$ 0.95 levels, but researchers should be aware of possible limitations in the application and appropriateness of these in relation to the area of research (e.g. psychometrics vs. organizational studies) and the low level of generalizability of this approach (cf. Marsh \& Hau 1996).

As the process of the second and third phases, the researcher should assess measures of absolute fit, incremental fit and model parsimony in detail. We present these measures in Appendix B.

\section{Research illustration}

We present recently published research papers from management literature as an illustration, which deal with similar research topic. The idea is to show the contemporary state of research performance using similar research topic, but executed by different researchers that apply various theoretical assumptions and research approaches. We present papers on brand loyalty / success published in the world-known peer reviewed journals such as Management Decision, Journal of the Academy of Marketing Science, Journal of Brand Management, etc. Labrecque et al. (2011) and Mazodier \& Marunka (2011) applied the CBSEM approach, and Hur et al. (2011) and Davcik \& Rundquist (2012) applied the VBSEM approach; presented in Table 5 .

\section{---- TAKE IN TABLE 5 ---}

Labrecque et al. (2011) and Mazodier \& Marunka (2011) applied their research on a convenient student sample group and a very few indices per construct (3 - 4), which is a minimum requirement and gives a good factor loading. They failed in theoretical justification of their research studies, because they had not explained and motivated reasons to apply the CBSEM approach, neither the relationships between indicators and constructs. As a reliability measure, they used only Cronbach's alpha indicator which is lower-bound to the reliability. Their assessment of the model fit is very poor. Labrecque et al. (2011) presented only chi-square, degrees of freedom, GFI, RMSEA, CFI, TLI and NFI; Mazodier \& Marunka (2011) applied only chi-square, RMSEA, CFI and NFI.

Hur et al. (2011) studied consumers and applied a very few indicators per construct (3.3 in average). This paper partly analyses reliability measures because they report composite reliability, but not report Cohen's f ${ }^{2}$. Assessment of the model was executed only partially and in a poor technical manner. The performance of the outer model in the model was not discussed at all. Therefore, the readers cannot be sure that predictive relevance is achieved and relative impact is substantial in the model. Stability of estimates is assessed only by the bootstrapping, but the authors failed to report the jack-knifing assessment of the model.

The study of Davcik \& Rundquist (2012) is a good example for the VBSEM approach. They justified theoretical approach due to the exploratory nature of study, data distribution assumptions and less stringent sample requirements in comparison to the CBSEM approach. The authors studied firms and their sample size is substantially smaller than in studies that put a consumer in research focus or student samples. However, their approach satisfies research and technical standards. This study presents all required reliability measures, indicators of model predictiveness and stability of estimates.

This short illustration shows typical research papers from management journals. Unfortunately, even recently published papers are executed in a weak theoretical and technical manner. We urge the editors and reviewers to pay more attention and effort to the theoretical justification of study, sample groups 
(because student sample cannot be useful and justification for theoretical generalizability) and poor technical performance of the reported studies.

\section{Conclusions, limitations and opportunities for future research}

This paper illustrates a common conceptual background for the variance-based and covariancebased SEM. Methodological analysis and comparison of the two SEM streams is the main contribution of this conceptual manuscript. We identified several common topics in our analysis. We discussed the covariance-based and variance-based SEM utilizing common topics such as (i) theory (theory background, relation to theory and research orientation); (ii) measurement model specification (type of latent construct, type of study, reliability measures, etc.); (iii) sample (sample size and data distribution assumption); and (iv) goodness-of-fit (measurement of the model fit and residual co/variance).

The two research approaches have substantial theoretical background differences. The CBSEM approach is based on a priori knowledge about the model (Fornell \& Bookstein 1982; Fornell 1983; Hair et al. 2010), because the researcher investigates the difference between the management reality and the hypothesized model. The VBSEM approach is framed by the theory, but its goal is to predict behavior among variables. In comparison to CBSEM which tends to confirm the underlying theory, the VBSEM approach tries to give exploratory meaning to theoretical foundations of the model.

The researcher can specify the measurement model in three modes: reflective, formative and mixed. Between the reflective- and formativeindicator constructs exist important methodological and practical differences. Almost 30\% of the models published in the top marketing journals were mistakenly specified (Jarvis et al. 2003), because the researchers did not pay attention to the appropriate specification of the measurement model and many formative constructs were incorrectly specified in the reflective mode. There is a debate in the academic community about the usefulness and applicability of formative measures (e.g., Howell et al. 2007; Wilcox et al. 2008; Bagozzi 2007; Diamantopoulos et al.
2008). For instance, Howell et al. (2007) have argued that formative measurement has very little usefulness and it is not an attractive alternative to the reflective measurement approach. Several other authors (e.g., Diamantopoulos et al. 2008) have suggested that formative measures are important but are underestimated by the management community. In the words of Diamantopoulos et al. (2008; p. 1216), "further theoretical and methodological research is necessary to finally settle this debate. Time will tell".

The requirements of the sample size in the SEM study differ in two streams. In general, the CBSEM study is more sensitive to sample size than the VBSEM study. The literature suggests that some statistical algorithms applied by CBSEM cannot produce trustworthy results (Hair et al. 2010) or that the researcher will have estimation problems with small samples. The VBSEM approach is more robust and less sensitive to sample size. Several simulations suggest that the study can be conducted with a sample of 20 observations and many latent constructs (e.g., Wold 1989; Chin \& Newsted 1999). However, small sample size and "soft" distributional prerequisites should not be employed as a "silver bullet" by default; i.e., without any sound reasons for theoretical and empirical justification.

The evaluation of fit and model selection are based on a great number of, and sometimes controversial, issues and criteria (e.g., Bentler 1990; Bentler \& Bonett 1980; Bollen 1989a, 1989b; Fornell \& Larcker 1981; Hair et al 2010; Hu \& Bentler 1999; Jöreskog 1973; Marsh \& Hau 1996; Tucker \& Lewis 1973). We synthesized and presented the minimum consensus that exists in SEM literature. This consensus represents different groups of measures and important conceptual differences between VBSEM and CBSEM approaches. The evaluation of the goodness-of-fit in the VBSEM approach includes assessment of the model predictability and the stability of estimates. A model evaluation in CBSEM includes assessment of different measures such as measures of absolute fit, incremental fit and model parsimony.

\subsection{Some remaining open questions}

An important research step is the problem of reliability. We have presented evidence against the 
usage of Cronbach's alpha in management studies, because alpha is not an appropriate reliability indicator, and $\lambda_{4}$ and GLB are more appropriate (e.g., Guttman 1945; Jackson \& Agunwamba 1977; Ten Berge \& Sočan 2004; Sijtsma 2009). The literature is silent about the behavior of the $\lambda_{4}$ and GLB in different measurement specification contexts. We know that a researcher can apply these reliability indicators in the type A mode, but we do not know whether we can also apply them in modes B and C. We also do not know if they are applicable only in the CBSEM set-up, or whether (and how) we can use them in the VBSEM set-up. From Werts et al. (1974) we know that the composite reliability $\rho_{\mathrm{c}}$ is a better indicator of reliability than Cronbach's $\alpha$ in the VBSEM approach. We do not know what the theoretical and practical interrelationships are, if any, among $\rho_{\mathrm{c}}$, Guttman's $\lambda$ and GLB in the VBSEM environment. Further software and theoretical development is needed.

An important issue is further scale modification, after the management scale has shown dimensionality and construct validity. Finn and Kayande (2004) have pointed out that effects of modified scale on scale performance is under-investigated in the literature, because scale adopted to a particular management context as well as scale refinement are not covered by classical reliability theory.

Researchers have tried to determine the minimum sample size needed for a study that employs the SEM approach, not only in management but also in other academic fields (e.g., Baumgartner \& Homburg 1996; Chin 1998; cf. Marcoulides \& Saunders 2006). For instance, we are not familiar with any research that questioned or extended Chin's "10" rule for a minimum sample size in the VBSEM environment (cf. Marcoulides \& Saunders 2006). The ongoing academic debate on how to corroborate the adequate sample size in both streams needs further theoretical enhancement and simulation studies, especially for a heterogeneous discipline such as management.

The conventional use of SEM employs linear models on cross-sectional data. There are two beneficial research avenues not employed in management. The first is the use of nonlinear models, such as quadratic effects of exogenous variables and Bayesian methods (e.g., Lee 2007). On the one hand, this application can open many new research opportunities for researchers, but on the other we must be aware of the limited use of this approach because variables that employ cross-sectional data are usually linear. The second beneficial avenue could be the employment of longitudinal data and time-series research. The SEM modeling of timeseries data is known in the literature as latent curve or latent growth modeling.

\subsection{Limitations of study}

This is a conceptual manuscript and a clear limitation is an absence of contributions and discussions based on empirical data. Empirical simulation, such as the Monte Carlo study, and an analysis of management data should be a logical continuation of this topic, but these enterprises are beyond the scope of this paper (cf. Tomarken \& Waller 2005). The complex CBSEM model that employs many latent constructs and indices, in three or more layers, is based on a high-dimensional integration of a parameter that cannot be efficiently estimated by standard maximum likelihood methods. The solution might be an application of Bayesian methods that are based on Markov Chain Monte Carlo (MCMC) estimation procedure (cf. Lee 2007). Management literature is scarce on empirical simulations and/or studies that analyze and compare conceptual foundations of covariance- and variancebased SEM. One of the few studies that do exist was conducted by Fornell and Bookstein (1982) almost 30 years ago, but was limited by their research scope, which focused only on differences in the measurement model specification. Tenenhaus (2008) made a simulation on the ESCI model, using customer satisfaction data, in which he compared CBSEM ("classical", PCA and ULS-SEM) and VBSEM (PLS and GSCA) approaches. He concluded that all approaches yielded practically the same results if the model specification was conducted correctly and the researcher used "good" data. This implies that model estimation is not dependent upon the method used, but on the underlying theoretical background, adequate sampling (cf. Churchill \& Peter 1984) and the correct model specification. Only a few studies in management literature analyze the measurement model specification, using Monte Carlo simulations, but exclusively in the CBSEM context 
(e.g., Diamantopoulos \& Winklhofer 2001; Jarvis et al. 2003; etc.), and they are silent about the VBSEM approach. We are aware of the marketing application of SEM in experimental designs by Bagozzi (1994) and Bagozzi and Yi (1989) that are applied in the CBSEM and VBSEM streams, but their findings and conceptualizations were not widely disseminated in the management community.

The second limitation is that we did not discuss the common method bias. This is an important issue in research practice but beyond the aim of this paper. However, researchers must be aware that most of the academic findings which are disseminated in the management community are based on self-reported research studies (Podsakoff \& Organ 1986). Problems with self-reporting arise because the subject is asked to express specific opinions and attitudes that can be questioned and changeable over time and in different environments. Research measures might be contaminated, causing measurement errors in informant reports, because all measures come from the same respondent, with the presumption that the source answers in the same fashion and via the same way of thinking (Podsakoff and Organ 1986; cf. Bagozzi et al. 1991). The researcher can apply two primary procedures to control common method biases: (i) the design of the study; and/or (ii) statistical tests (Podsakoff et al. 2003). Common method bias is traditionally tackled by Harman's one-factor test (Harman 1967) in order to control common method variance. All variables are entered into a factor analysis in this procedure. The unrotated factor solution results are examined in order to determine the number of factors that account for the variance in examined variables (Podsakoff \& Organ 1986), applying the commonly accepted threshold for the eigenvalue above value 1 . The correlated uniqueness model has been suggested as an appropriate approach to tackle the estimation problems within the MTMM model (Podsakoff et al. 2003), because this model allows the error terms to be correlated in order to account for the measurement effects by the same method (Podsakoff et al. 2003). The common method bias techniques are based on the classical test theory, which means that indicators are formed in the type A mode, i.e., as the reflectiveindicator constructs. This implies two problems that are not addressed in the literature. First, how the common method bias remedies are applied within formative and mixed models. The difference between the formative and reflective constructs is an important issue because of the source of common method bias. The error term in the reflective mode is identified at the indicator level, but in the formative mode the error resides at the construct level. Formative constructs in the CBSEM approach are identified if there are at least two additional reflective paths that emanate from the construct (Podsakoff et al. 2003). Second, the current body of knowledge assumes that common method biases are applied in the CBSEM environment. The literature is also silent about the matter of what the common method remedies will be if the researcher applies the VBSEM approach.

In our view, it is important that future theoretical enhancements and simulation studies in management address these issues in detail.

\section{References}

Anderson, J. and Gerbing D. (1982). "Some Methods for Respecifying Measurement Models to Obtain Unidimensional Construct Measurement", Journal of Marketing Research, XIX (November), 453-460

Anderson, J. and Gerbing D.(1988). "Structural Equation Modeling in Practice: A Review and Recommended Two-Step Approach", Psychological Bulletin, 103 (3), 411-423

Bagozzi, R. P. (1994). "Structural Equation Models in Marketing Research: Basic Principles", in Principles of Marketing Research, R.P. Bagozzi, ed., Oxford: Blackwell Publishers, 125-140

Bagozzi, R. P. (2007). "On the Meaning of Formative Measurement and How It Differs from Reflective Measurement: Comment on Howell, Breivik, and Wilcox (2007)", Psychological_Methods, 12 (2), 229-237

Bagozzi, R. P. and Phillips L. (1982).

"Representing and Testing Organizational Theories: A Holistic Construal", Administrative Science Quarterly, 27 (September), 459-489

Bagozzi, R. P. and Youjae Yi (1989). "On the Use of Structural Equation Models in Experimental 
Designs", Journal of Marketing Research, 26 (3), 271-284

Bagozzi, R. P., Youjae Yi and Lynn W. Phillips (1991). "Assessing Construct Validity in Organizational Research", Administrative Science Quarterly, 36 (September), 421-458

Baumgartner, H. and Homburg C.(1996). "Applications of structural equation modeling in marketing and consumer research: A review", International Journal of Research in Marketing, 13 (2), 139-161

Bentler, P.M. (1990). "Comparative fit index in structural models", Psychological Bulletin, 107 (2), 238-246

Bentler, P.M. and D.G. Bonett (1980). "Significance test and goodness-of-fit in the analysis of covariance structures", Psychological Bulletin, 88 (3), 588-606

Blalock, H. (1964). Causal Inferences in Nonexperimental Research. Chapel Hill: University of North Carolina Press

Bollen, K. (1984). "Multiple Indicators: Internal Consistency or No Necessary Relationship", Quality and Quantity, 18 (4), 377-385

Bollen, K. (1989). "A New Incremental Fit Index for General Structural Models", Sociological Methods \& Research, 17 (3), 303-316

Bollen, K. and Richard Lennox (1991). "Conventional Wisdom on Measurement: A Structural Equation Perspective". Psychological Bulletin, 110 (2), 305-314

Byrne, B. (1998). Structural Equation Modeling with LISREL, PRELIS and SIMPLIS: Basic Concepts, Applications, and Programming. Mahwah: Lawrence Erlbaum Associates

Cenfetelli, R. and G. Bassellier (2009). "Interpretation of Formative Measurement in Information Systems Research". MIS Quarterly, 33 (4), 689-707

Chin, W. (1998). "The Partial Least Squares Approach to Structural Equation Modeling", in Modern Methods for Business Research, Marcoulides G.A., ed. Mahwah: Lawrence Erlbaum Associates, 295-358

Chin, W. and P.R. Newsted (1999). Structural equation modeling analysis with small samples using partial least squares. In Statistical strategies for small sample research, Hoyle, R. H., ed. Thousand Oaks: Sage, 307-342

Chintagunta, P., T. Erdem, Peter E. Rossi and M. Wedel (2006). "Structural Modeling in Marketing: Review and Assessment". Marketing Science, 25 (6), 604-616

Churchill, G. (1979). "A Paradigm for Developing Better Measures of Marketing Constructs".
Journal of Marketing Research, XVI

(February), 64-73

Churchill, G. and P. Peter (1984). "Research Design Effects on the Reliability of Rating Scales: A Meta-Analysis". Journal of Marketing Research, XXI (November), 360-375

Cohen, J. (1988). Statistical power analysis for the behavioral sciences, $2^{\text {nd }}$ ed., Hillsdale: Lawrence Erlbaum Ass.

Cohen, J. (1991). “A Power Primer”, Psychological Bulletin, 112 (1), 155-159

Coltman, T., T. Devinney, D. Midgley and S. Venaik (2008). "Formative versus reflective measurement models: Two applications of formative measurement", Journal of Business Research, 61 (12), 1250-1262

Cronbach, L. (1951). "Coefficient Alpha and the Internal Structure of Tests". Psychometrika, 16 (3), 297-334

Cronbach, L., G. Gleser, H. Nanda and N. Rajaratnam (1972). The Dependability of Behavioral Measurements: Theory of Generalizability for Scores and Profiles. New York: John Wiley \& Sons

Curtis, R. and Elton F. Jackson (1962). "Multiple indicators in survey research", American Journal of Sociology, 68 (2), 195-204

Davcik, N. S. and J. Rundquist (2012). "An exploratory study of brand success: Evidence from the food industry", Journal of International Food and Agribusiness Marketing, 24 (1), 91-109; DOI: 10.1080/08974438.2012.645747

Diamantopoulos, A., P. Riefler and K. Roth (2008). "Advancing formative measurement models", Journal of Business Research, 61 (12), 1203-' 1218

Diamantopoulos, A. and J. Siguaw (2006). "Formative Versus Reflective Indicators in Organizational Measure Development: A Comparison and Empirical Illustration", British Journal of Management, 17 (4), 263 282

Diamantopoulos, A. and H. Winklhofer (2001). "Index Construction with Formative Indicators: An Alternative to Scale Development", Journal of Marketing Research, XXXVIII (May), 269-277

Edwards, J. and R. Bagozzi (2000). "On the Nature and Direction of Relationships Between Constructs and Measures (lead article)", Psychological Methods, 5 (2), 155-174.

Efron, B. (1979). "Bootstrap Methods: Another Look at the Jackknife". The Annals of Statistics, 7 (1), 1-26 
Efron, B. (1981). "Nonparametric Estimates of Standard Error: The Jackknife, the Bootstrap and Other Methods". Biometrika, 68 (3), 589599

Faul, F., E. Erdfelder, A. Buchner and Albert-Georg Lang (2009). "Statistical power analyses using $G^{*}$ Power 3.1: Test for correlation and regression analyses". Behavior Research Methods, 41 (4), 1149-1160

Finn, A. and U. Kayande (1997). "Reliability Assessment and Optimization of Marketing Measurement". Journal of Marketing Research, XXXIV (May), 262-275

Finn, A. and U. Kayande (2004). "Scale modification: alternative approaches and their consequences". Journal of Retailing, 80 (1), 37-52

Finn, A. and U. Kayande (2005). "How fine is COAR-SE? A generalizability theory perspective on Rossiter's procedure". International Journal of Research in Marketing, 22 (1), 11-21

Fornell, C., D. Barclay and Byong-Duk Rhee (1988). "A model and simple iterative algorithm for redundancy analysis". Multivariate Behavioral Research, 23 (3), 349360

Fornell, C. and F. Bookstein (1982). "Two structural Equation Models: LISREL and PLS Applied to Consumer Exit-Voice Theory". Journal of Marketing Research, XIX (November), 440-452

Fornell, C. and D. Larcker (1981). "Evaluating Structural Equation Models with Unobservable Variables and Measurement Error", Journal of Marketing Research, XVIII (February), 39-50

Gatignon, Hubert (2003). Statistical Analysis of Management Data, Dordrecht: Kluwer Academic Publishers

Geisser, S. (1974). "A Predictive Approach to the Random Effect Model”, Biometrika, 61 (1), 101-107

Geisser, S. (1975). "The Predictive Sample Reuse Method with Applications". Journal of the American Statistical Association, 70 (June), 320-328

Gerbing, D. and J. Anderson (1988). “An Updated Paradigm for Scale Development Incorporating Unidimensionality and Its Assessment". Journal of Marketing Research, 25 (2), 186192

Guttman, L. (1945). "A basis for analyzing testretest reliability". Psychometrika, 10 (4), 255282
Hair, J., W. Black, B. Babin, R. Anderson (2010). Multivariate data analysis, $7^{\text {th }}$ ed., Prentice Hall

Hair, J., M. Sarstedt, C. Ringle and J. Mena (2012). "An assessment of the use of partial least squares structural equation modeling in marketing research", Journal of the Academy of Marketing Science, 40(3), 414-433

Harman, H. (1967). Modern factor analysis, $2^{\text {nd }}$ ed., Chicago: University of Chicago Press

Henseler, J., C. Ringle and R. Sinkovics (2009). "The use of partial least squares path modeling in international marketing". Advances in International Marketing, 20, 277-319

Howell, R., E. Breivik and J. Wilcox (2007). "Reconsidering Formative Measurement". Psychological Methods, 12 (2), 205-218

Hoyt, C. (1941). "Test reliability estimated by analysis of variance". Psychometrika, 6 (3), 153-160

Hu, Li-tze and P.M. Bentler (1998). "Fit indices in covariance structure modeling: Sensitivity to underparameterized model misspecification". Psychological Methods, 3 (4), 424-453

Hu, Li-tze and P.M. Bentler (1999). "Cutoff criteria for fit indexes in covariance structure analysis: Conventional criteria versus new alternatives". Structural Equation Modeling, 6 (1), 1-55

Hur, Won-Moo, Kwang-Ho Ahn and Minsung Kim (2011). "Building brand loyalty through managing brand community commitment". Management Decision, 49 (7), 1194-1213

Jackson, P. and C. Agunwamba (1977). "Lower bounds for the reliability of the total score on a test composed of non-homogenous items: I: Algebraic lower bounds". Psychometrika, 42 (4), 567-578

Jackson, R.W. and G.A. Ferguson (1941). "Studies on the reliability of tests". Bulletin No. 12, University of Toronto, Toronto

Jarvis, C., S. MacKenzie and P. Podsakoff (2003). "A Critical Review of Construct Indicators and Measurement Model Misspecification in Marketing and Consumer Research". Journal of Consumer Research, 30 (September), 199218

Jöreskog, K. (1966). "Testing a simple structure hypothesis in factor analysis". Psychometrika, 31 (2), 165-178

Jöreskog, K. (1967). "Some contributions to maximum likelihood factor analysis". Psychometrika, 32 (4), 443-482

Jöreskog, K. (1969). "A general approach to confirmatory maximum likelihood factor analysis". Psychometrika, 34 (2), 183-202 
Jöreskog, K. (1970). “A General Method for Analysis of Covariance Structures". Biometrika, 57 (2), 293-351

Jöreskog, K. (1973). “A General Method for Estimating a Linear Structural Equation System", in Structural equation models in the social sciences, Arthur S. Goldberg \& Otis D. Duncan, eds. New York: Seminar Press, 85112

Jöreskog, K. (1979). "Structural Equation Models in the Social Sciences: Specification, Estimation and Testing", in Advances in Factor Analysis and Structural Equation Models, Karl G. Jöreskog and Dag Sörbom, eds. Cambridge: ABT Books, 105-127

Jöreskog, K.and D. Sörbom (1996). LISREL 8: User's Reference Guide, Chicago: Scientific Software International

Jöreskog, K.and H. Wold (1982). "The ML and PLS technique for modeling with latent variables: Historical and comparative aspects", in Systems under indirect observations: Causality, structure, prediction (part I), Jöreskog, K.G. \& H. Wold, eds. Amsterdam: North-Holland, 263-270

Kenny, D. and D. Betsy McCoach (2003). "Effect of the Number of Variables on Measures in Structural Equation Modeling". Structural Equation Modeling, 10 (3), 333-351

Kuder, G.F. and M.W. Richardson (1937). "The theory of the estimation of test reliability". Psychometrika, 2 (3), 151-160

Labrecque, L., A. Krishen and S. Grzeskowiak (2011). "Exploring social motivations for brand loyalty: Conformity versus escapism". Journal of Brand Management, 18 (7), 457472

Lee, Sik-Yum (2007). Structural Equation Modeling, A Bayesian Approach, West Sussex: Wiley

MacKenzie, S. (2001). "Opportunities for Improving Consumer Research through Latent Variable Structural Equation Modeling”. Journal of Consumer Research, 28 (June), 159-166

MacKenzie, S., P. Podsakoff and C. Jarvis (2005). "The problem of Measurement Model Misspecification in Behavioral and Organizational Research and Some Recommended Solutions". Journal of Applied Psychology, 90 (4), 710-730

Marcoulides, G. and Carol Saunders (2006). "PLS: A Silver Bullet". MIS Quarterly, 30 (2), iii-ix

Marsh, H. and Kit-Tai Hau (1996). "Assessing Goodness of Fit: Is Parsimony Always
Desirable?". Journal of Experimental

Education, 64 (4), 364-390

Marsh, H., Kit-Tai Hau and Z. Wen (2004). "In Search of Golden Rules: Comment on Hypothesis-Testing Approaches to Setting Cutoff Values for Fit Indexes and Dangers in Overgeneralizing Hu and Bentler's (1999) Findings". Structural Equation Modeling, 11 (3), 320-341

Mazodier, M. and D. Merunka (2011). "Achieving brand loyalty through sponsorship: the role of fit and self-congruity". Journal of the Academy of Marketing Science, DOI: 10.1007/s11747011-0285-y

McDonald, Roderick P. (1996). "Path Analysis with Composite Variables". Multivariate Behavioral Research, 31 (2), 239-270

Nunnally, J. and I. Bernstein (1994). Psychometric theory, $3^{\text {rd }}$ ed., New York: McGraw-Hill

Peter, P. (1979). "Reliability: A Review of Psychometric Basics and Recent Marketing Practices". Journal of Marketing Research, XVI(February), 6-17

Peter, P. (1981). "Construct Validity: A Review of Basic Issues and Marketing Practices". Journal of Marketing Research, 18 (May), 133-145

Podsakoff, P., S. MacKenzie, J. Lee and N. Podsakoff (2003). "Common Method Biases in Behavioral Research: A Critical Review of the Literature and Recommended Remedies". Journal of Applied Psychology, 88 (5), 879903

Podsakoff, P. and D. Organ (1986). "Self-Reports in Organizational Research: Problems and Prospects". Journal of Management, 12 (Winter), 531-544

Reinartz, W., M. Haenlein and J. Henseler (2009). "An empirical comparison of the efficacy of covariance-based and variance-based SEM". International Journal of Research in Marketing, 26(4), 332-344

Rossiter, J. (2002). "The C-OAR-SE procedure for scale development in marketing". International Journal of Research in Marketing, 19(4), 305335

Schreiber, J., N. Amaury, F. Stage, E. Barlow and J. King (2006). "Reporting Structural Equation Modeling and Confirmatory Factor Analysis: A Review". The Journal of Educational Research, July-August, 99 (6), 323-337

Shook, C., D. Ketchen, T. Hult and K. Michele Kacmar (2004). "An Assessment of the Use of Structural Equation Modeling in Strategic Management Research". Strategic Management Journal, 25 (4), 397-404 
Sijtsma, K. (2009). "On the use, the misuse, and the very limited usefulness of Cronbach's Alpha". Psychometrika, 74 (1), 107-120

Steiger, James H. (1990). "Structural Model Evaluation and Modification: An Interval Estimation Approach". Multivariate Behavioral Research, 25 (2), 173-180

Stone, M. (1974). "Cross-Validatory Choice and Assessment of Statistical Predictions". Journal of the Royal Statistical Society, Series B (Methodological), 36 (2), 111-147

Ten Berge, Jos M.F. and Henk A.L. Kiers (1991). "A numerical approach to the exact and the and the approximate minimum rank of a covariance matrix". Psychometrika, 56 (2), 309-315

Ten Berge, J.F. and G. Sočan (2004). "The greatest lower bound to the reliability of a test and the hypothesis of unidimensionality". Psychometrika, 69 (4), 613-625

Tenenhaus, M. (2008). "Component-based Structural Equation Modelling”. Total Quality Management, 19 (7-8), 871-886

Tomarken, A. and N. Waller (2005). "Structural Equation Modeling: Strengths, Limitations, and Misconceptions". Annual Review of Clinical Psychology, 1, 31-65

Tucker, Ledyard R. and Charles Lewis (1973). "The Reliability Coefficient for Maximum Likelihood Factor Analysis". Psychometrika, 38 (1), 1-10

Werts, C.E., Linn, R.L. and Karl G. Jöreskog (1974). "Intraclass reliability estimates: Testing structural assumptions". Educational and Psychological Measurement, 34 (1), 25-33

Wetzels, Martin, Gaby Odekerken-Schröder and Claudia van Oppen (2009). "Using PLS Path Modeling for Assessing Hierarchical Construct Models: Guidelines and Empirical Illustration". MIS Quarterly, 33 (1), 177-195

Wilcox, J., R. Howell and E. Breivik (2008). "Questions about formative measurement".
Journal of Business Research, 61 (12), 12191228

Wiley, D.E. (1973). "The identification problem for structural equation models with unmeasured variables", in Structural equation models in the social sciences, Arthur S. Goldberg \& Otis D. Duncan, eds. New York: Seminar Press, 69-83

Wold, H. (1973). "Nonlinear iterative partial least squares (NIPALS) modeling: Some current developments", in Multivariate analysis: II. Proceedings of an international symposium on multivariate analysis, P.R. Krishnaiah, ed. New York: Academic Press, June 19-24 1972, 383-407

Wold, H. (1975). "Path Models with Latent Variables: The NIPALS Approach", in Quantitative Sociology: International Perspectives on Mathematical and Statistical Model Building, H.M. Blalock et al., eds. New York: Academic Press, 307-357

Wold, H. (1980). "Model construction and evaluation when theoretical knowledge is scarce: Theory and application of partial least squares", in Evaluation of econometric models, Kmenta, J. \& J.B. Ramsey, eds. New York: Academic Press, 47-74

Wold, H. (1982). "Soft modeling: the basic design and some extensions", in Systems under indirect observations: Causality, structure, prediction (part II), Jöreskog, K.G. \& H. Wold, eds. Amsterdam: North-Holland, 1-54

Wold, H. (1989). "Introduction to the second generation of multivariate analysis", in Theoretical empiricism: A general rationale for scientific model-building, Wold, H.O., ed. New York: Paragon House, VIII-XL

Yuan, Ke-Hai , C. Kouros and K. Kelley (2008). "Diagnosis for Covariance Structure Models by Analyzing the Path", Structural Equation Modeling, 15 (4), 564-602 
Table 1: Structural equation modeling: CBSEM \& VBSEM

\begin{tabular}{|c|c|c|c|}
\hline \multirow{2}{*}{\multicolumn{2}{|c|}{ TOPIC }} & \multicolumn{2}{|c|}{ S E M } \\
\hline & & COVARIANCE (CBSEM) & VARIANCE (VBSEM) \\
\hline \multirow{3}{*}{$\begin{array}{l}\stackrel{\overrightarrow{0}}{0} \\
\stackrel{0}{E}\end{array}$} & Theory background & strictly theory driven & based on theory, but data driven \\
\hline & Relation to the theory & confirmatory & predictive \\
\hline & Research orientation & parameter & prediction \\
\hline \multirow{7}{*}{ 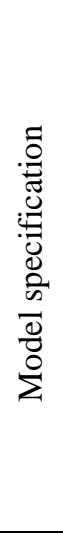 } & $\begin{array}{l}\text { Type of the latent measures } \\
\text { (constructs) }\end{array}$ & $\begin{array}{l}\text { reflective indicators (and formative, if identified by } \\
\text { reflective) }\end{array}$ & reflective and/or formative indicators \\
\hline & Latent variables & $\begin{array}{l}\text { factors } \\
\end{array}$ & components \\
\hline & Model parameters & factor means & component weights \\
\hline & Type of study & psychometric analysis (attitudes, purchase intention, etc.) & $\begin{array}{l}\text { drivers of success, organizational constructs (market / } \\
\text { service / consumer orientation, sales force, employees, } \\
\text { etc.) }\end{array}$ \\
\hline & Structure of unobservables & indeterminate & determinate \\
\hline & Reliability measures & Cronbach's $\alpha$ (and / or Guttman's $\lambda$ and GLB) & $\begin{array}{c}\text { a) Cohen's } f^{2} \\
\text { b) } \rho_{\mathrm{c}} \text { indicator or Cronbach's } \alpha \text {, Guttman's } \lambda \text { and } \\
\text { GLB (for the reflective models only) }\end{array}$ \\
\hline & Input data & covariance / correlation matrix & individual-level raw data \\
\hline \multirow[t]{2}{*}{ 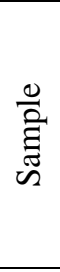 } & Sample size & $\begin{array}{l}\text { ratio of sample size to free model parameters }- \text { minimum } 5 \\
\text { observations to } 1 \text { free parameter, optimum is } 10\end{array}$ & $\begin{array}{l}\text { a) Ten observations multiplied with the construct that } \\
\text { has highest number of indicators } \\
\text { b) The endogenous construct with the largest number } \\
\text { of exogenous constructs, multiplied with ten } \\
\text { observations }\end{array}$ \\
\hline & Data distribution assumption & identical distribution & "soft" modeling, identical distribution is not assumed \\
\hline \multirow[t]{3}{*}{ 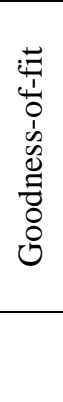 } & Assessment of the model fit & $\begin{array}{l}\text { a) Overall (absolute) fit measures } \\
\text { b) Comparative (incremental) fit measures } \\
\text { c) Model parsimony }\end{array}$ & $\begin{array}{l}\text { a) Model predictiveness (coefficient of } \\
\text { determination, } \mathrm{Q}^{2} \text { predictive relevance and average } \\
\text { variance extracted - AVE) } \\
\text { b) Stability of estimates, applying the resampling } \\
\text { procedures (jack-knifing and bootstrapping). }\end{array}$ \\
\hline & Residual co/variance & $\begin{array}{l}\text { residual covariances are minimized for optimal parameter } \\
\text { fit }\end{array}$ & $\begin{array}{l}\text { residual variances are minimized to obtain optimal } \\
\text { prediction }\end{array}$ \\
\hline & Software & LISREL, AMOS, etc. & SmartPLS, SPSS (PLS module), etc. \\
\hline
\end{tabular}


Table 2: Indicators: RI \& FI

\begin{tabular}{|c|c|c|c|}
\hline \multirow{2}{*}{\multicolumn{2}{|c|}{ TOPICS }} & \multicolumn{2}{|c|}{ Indicators } \\
\hline & & REFLECTIVE (RI) & FORMATIVE (FI) \\
\hline \multirow{8}{*}{ 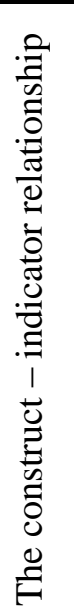 } & Direction of causality & from the construct to the measure (indicator) & from the measure (indicator) to the construct \\
\hline & $\begin{array}{l}\text { Theoretical framework (type of the } \\
\text { constructs) }\end{array}$ & psychometric constructs (attitudes, personality, etc.) & $\begin{array}{c}\text { organizational constructs (marketing mix, drivers of } \\
\text { success, performances, etc.) }\end{array}$ \\
\hline & $\begin{array}{l}\text { The latent construct is empirically } \\
\text { defined }\end{array}$ & common variance & total variance \\
\hline & $\begin{array}{l}\text { The indicators relationship to the same } \\
\text { antecedents and consequences }\end{array}$ & required & not required \\
\hline & Internal consistency reliability & implied & not implied \\
\hline & Validity of constructs & internal consistency reliability & nomological and / or criterion-related validity \\
\hline & Indicator omission from the model & does not influence the construct & may influence the construct \\
\hline & Number of indicators per construct & minimum 3 & $\begin{array}{c}\text { i) In VBSEM: Conceptually dependent } \\
\text { ii) In CBSEM: min } 3 \text { formative, with } 2 \text { reflective } \\
\text { for identification }\end{array}$ \\
\hline \multirow{5}{*}{ 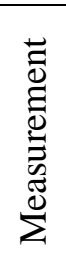 } & Measurement error & at the indicator level & at the construct level \\
\hline & Interchangeability & expected & not expected \\
\hline & Multicollinearity & expected & not expected \\
\hline & $\begin{array}{l}\text { Development of the multi-item } \\
\text { measures }\end{array}$ & scale & index \\
\hline & Nomological net of the indicators & should not differ & may differ \\
\hline
\end{tabular}


Table 3: Preferred value of the Cronbach's Alpha, $\rho_{\mathrm{c}}$ indicator, Guttman's $\lambda$, GLB and Cohen's $f$ square indicators

\begin{tabular}{|c|c|c|}
\hline & $\begin{array}{c}\text { Cronbach's } \alpha \& \rho_{\mathrm{c}} \text { indicator (and / or } \\
\text { Guttman's } \lambda \text { and GLB) }\end{array}$ & Cohen's $f$-square \\
\hline Preferred value & $\begin{array}{l}\text { i) } 0.60-0.70 \text { for multi-item constructs } \\
\text { (minimum) } \\
\text { ii) } \geq 0.70 \text { preferred for multi-item } \\
\text { constructs } \\
\text { iii) } \geq 0.80 \text { for single-item constructs } \\
\text { (minimum) }\end{array}$ & $\begin{array}{l}\text { i) } 0.02 \text { - weak effect } \\
\text { ii) } 0.15 \text { - medium effect } \\
\text { iii) } 0.35 \text { - strong effect }\end{array}$ \\
\hline
\end{tabular}


Table 4: Research illustration

\begin{tabular}{|c|c|c|c|c|c|c|c|}
\hline CRITERION & \multicolumn{3}{|c|}{ TOPIC ASSESSMENT } & HUR et al. 2011 & $\begin{array}{c}\text { DAVCIK \& } \\
\text { RUNDQUIST } 2012 \\
\end{array}$ & $\begin{array}{c}\text { LABRECQUE et al. } \\
2011 \\
\end{array}$ & $\begin{array}{c}\text { MAZODIER \& } \\
\text { MARUNKA 2011 } \\
\end{array}$ \\
\hline $\begin{array}{l}\text { Justification of } \\
\text { theoretical approach }\end{array}$ & \multicolumn{3}{|c|}{ If YES, motivation } & $\begin{array}{c}\text { YES, because of "minimal } \\
\text { restrictions on sample size } \\
\text { and residual distribution" }(p . \\
1202) \\
\end{array}$ & $\begin{array}{l}\text { YES, because of exploratory } \\
\text { nature of the study, data } \\
\text { distribution assumptions and less } \\
\text { stringent sample requirements }\end{array}$ & 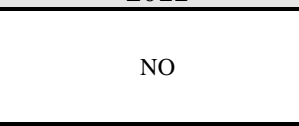 & 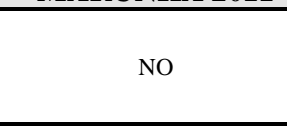 \\
\hline $\begin{array}{l}\text { Type of the latent } \\
\text { measures }\end{array}$ & \multicolumn{3}{|c|}{ Reflective, formative or mixed } & Reflective & Mixed & $\begin{array}{l}\text { ?(Not stated, but we can } \\
\text { assume reflective) }\end{array}$ & $\begin{array}{l}\text { ? (Not stated, but we can } \\
\text { assume reflective) }\end{array}$ \\
\hline Type of study & \multicolumn{3}{|c|}{ Confirmatory, exploratory, etc. } & $\begin{array}{l}\text { ? (Not stated, but the nature } \\
\text { of study is exploratory) }\end{array}$ & exploratory & $\begin{array}{l}\text { ? (Not stated, but the nature } \\
\text { of study is exploratory) }\end{array}$ & $\begin{array}{l}\text { ? (Not stated, but the nature } \\
\text { of study is confirmatory) }\end{array}$ \\
\hline \multirow{5}{*}{ Reliability measures } & \multirow{3}{*}{ CBSEM } & \multicolumn{2}{|l|}{ Cronbach's $\alpha$} & & & + & + \\
\hline & & \multicolumn{2}{|l|}{ Guttman's $\lambda$} & & & -- & -- \\
\hline & & \multicolumn{2}{|l|}{ GLB } & & & -- & -- \\
\hline & \multirow{2}{*}{ VBSEM } & \multicolumn{2}{|l|}{ Cohen's $f^{2}$} & -- & + & & \\
\hline & & \multicolumn{2}{|c|}{ Composite reliability $\rho_{\mathrm{c}}$ (or $\alpha, \lambda$ or GLB) } & + & + & & \\
\hline Sample size & & & & 200 & 58 & 330 & 449 \\
\hline Sample group & \multicolumn{3}{|c|}{ (consumers, firms, students, etc.) } & Consumers & Firms & Students & Students \\
\hline No. of constructs & & & & 6 & 7 & 7 & 7 \\
\hline No. of indicators & & & & 20 & 37 & 27 & 21 \\
\hline \multirow{22}{*}{ 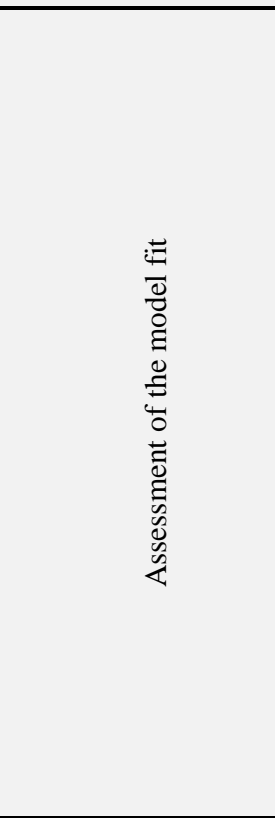 } & \multirow{16}{*}{ 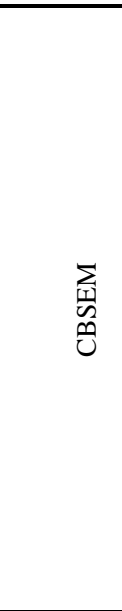 } & \multirow{7}{*}{ Overall fit measures } & Chi-square $\left(\chi^{2}\right)$ & & & + & + \\
\hline & & & degrees of freedom $(\mathrm{df})$ & & & + & -- \\
\hline & & & Chi-square / df ratio & & & -- & -- \\
\hline & & & Goodness-of-fit index (GFI) & & & + & -- \\
\hline & & & Root mean square residual (RMSR) & & & -- & -- \\
\hline & & & $\begin{array}{l}\text { Root mean square error of } \\
\text { approximation (RMSEA) }\end{array}$ & & & + & + \\
\hline & & & Confidence interval of RMSEA & & & -- & -- \\
\hline & & \multirow{6}{*}{$\begin{array}{l}\text { Comparative fit } \\
\text { measures }\end{array}$} & Comparative fit index (CFI) & & & + & + \\
\hline & & & Incremental fit index (IFI) & & & -- & -- \\
\hline & & & Tucker - Lewis index (TLI / NNFI) & & & + & -- \\
\hline & & & Relative non-centrality index (RNI) & & & -- & -- \\
\hline & & & Relative fit index $(\mathrm{RFI})$ & & & -- & -- \\
\hline & & & Normed fit index (NFI) & & & + & + \\
\hline & & \multirow{3}{*}{ Model parsimony } & $\begin{array}{l}\text { Adjusted goodness-of-fit index } \\
\text { (AGFI) }\end{array}$ & & & -- & -- \\
\hline & & & Parsimony normed fit index (PNFI) & & & -- & -- \\
\hline & & & Parsimony ratio $\psi$ & & & -- & -- \\
\hline & \multirow{6}{*}{$\begin{array}{l}\sum_{\text {II }} \\
\underbrace{\infty} \\
>\end{array}$} & \multirow{4}{*}{$\begin{array}{l}\text { Model } \\
\text { predictiveness }\end{array}$} & Coefficient of determination & + & + & & \\
\hline & & & $\mathrm{Q}^{2}$, predictive relevance & -- & + & & \\
\hline & & & $\mathrm{q}^{2}$, relative impact & -- & + & & \\
\hline & & & AVE & + & + & & \\
\hline & & \multirow{2}{*}{$\begin{array}{l}\text { Stability of } \\
\text { estimates }\end{array}$} & Jack-knifing (yes / no) & no & yes & & \\
\hline & & & Bootstrapping (yes / no) & yes & yes & & \\
\hline
\end{tabular}




\section{APPENDIX A - Types of latent constructs}

The simplified structural models with the reflective and/or formative constructs are represented in Figures A.1, A.2 and A.3. A circle or ellipsis represents an unobserved or latent variable; a square represents an observed or manifest variable (cf. Bagozzi \& Phillips 1982). An arrow that indicates a direction between a circle and square represents the effects of a latent variable on its measure in the first order reflective construct and, vice versa, the effects of a manifest variable on a latent variable in the first-order formative construct.

These figures use "classical" SEM notation that needs some attention. $\xi$ (ksi) represents a latent construct associated with observed $\mathrm{x}_{\mathrm{i}}$ indicators, $\eta$ (eta) stands for a latent construct associated with observed $\mathrm{y}_{\mathrm{i}}$ indicators, the error terms $\delta_{\mathrm{i}}\left(\right.$ delta) and $\varepsilon_{\mathrm{i}}$ (epsilon) are associated with observed $x_{i}$ and $y_{i}$ indicators, respectively. $\zeta$ (zeta) is the error term associated with the formative construct. $\lambda_{\mathrm{ij}}$ represents factor loading in the $i$-th observed indicator that is explained by the $j$-th latent construct. $\gamma_{\mathrm{ij}}$ represents weight in the $i$-th observed indicator that is explained by the $j$-th latent construct.

Figure A.1 depicts the "classical" SEM case where the model is specified in the reflective mode. The type A case depicts a path diagram between the two latent constructs $(\xi$ - exogenous and $\eta$ - endogenous), with three indicators per construct $\left(\mathrm{x}_{\mathrm{i}}\right.$ and $\left.\mathrm{y}_{\mathrm{i}}\right)$. This case can be represented by equations 1 and 2 :

$$
\begin{array}{ll}
\text { (A.1) } & \mathrm{x}_{\mathrm{i}}=\lambda_{\mathrm{ij}} \xi+\delta_{\mathrm{i}} \\
\text { (A.2) } & \mathrm{y}_{\mathrm{i}}=\lambda_{\mathrm{ij}} \eta+\varepsilon_{\mathrm{i}}
\end{array}
$$

This specification assumes that the error term is unrelated to the latent variable $\operatorname{COV}\left(\eta, \varepsilon_{\mathrm{i}}\right)=0$, and independent $\operatorname{COV}\left(\varepsilon_{\mathrm{i},}, \varepsilon_{\mathrm{j}}\right)=0$, for $i \neq j$ and expected value of error term $E\left(\varepsilon_{\mathrm{i}}\right)=0$. This type of model specification is typical for the classical test theory and factor analysis models (Fornell \& Bookstein 1982; Bollen \& Lennox 1991; Chin 1998; Diamantopoulos \& Winklhofer 2001) used in behavioral studies.

Figure A.1 - Type A: Latent constructs with reflective indicators

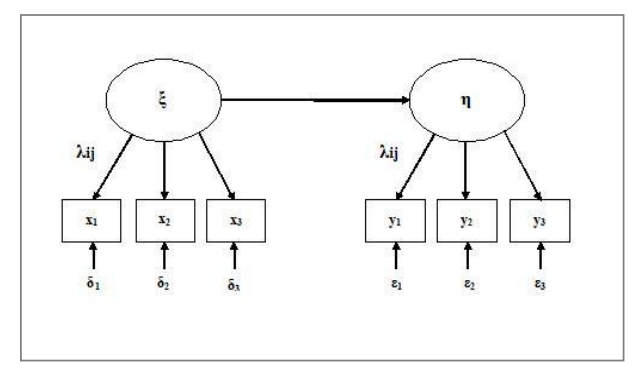

The type B model specification, presented in Figure A.2, is known as a formative (Fornell \& Bookstein 1982) or causal indicator (Bollen and Lennox 1991), because the direction of causality goes from the indicators (measures) to the construct and the error term is estimated at the construct level. This type of model specification can be represented by equations A.3 and A.4:

(3) $\xi_{\mathrm{j}}=\gamma_{\mathrm{ij}} \mathrm{x}_{\mathrm{i}}+\zeta_{\mathrm{j}}$

(4) $\eta_{\mathrm{j}}=\gamma_{\mathrm{ij}} \mathrm{y}_{\mathrm{i}}+\zeta_{\mathrm{j}}$

This specification assumes that the indicators and error term are not related, i.e. $\operatorname{COV}\left(\mathrm{y}_{\mathrm{i}}, \zeta_{\mathrm{j}}\right)=0$, and $E\left(\zeta_{\mathrm{j}}\right)=0$

Figure A.2 - Type B: Latent constructs with formative indicators

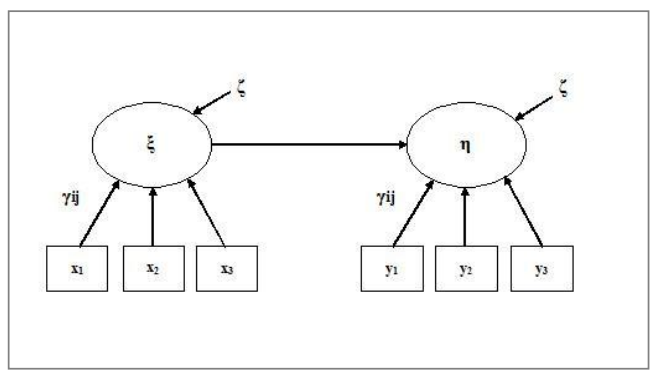

The mixed case is represented by Figure A.3. The researcher can create a model that uses both formative and reflective indicators.

Figure A.3 - Type C: Latent constructs with reflective and formative indicators

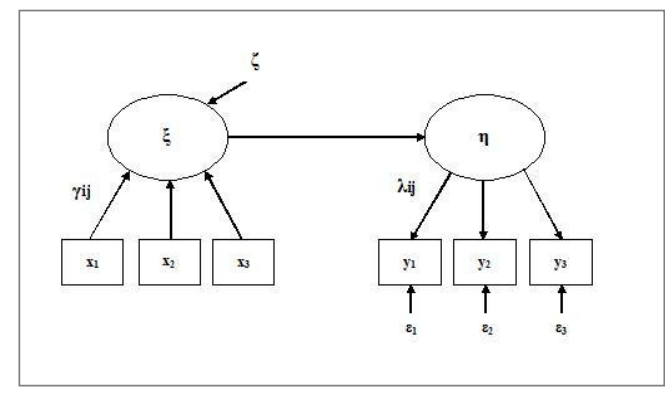




\section{APPENDIX B - Goodness-of-fit}

Goodness-of-fit in VBSEM: The $\mathrm{Q}^{2}$ predictive relevance indicator, the relative impact of the predictive relevance and average variance extracted

The $\mathrm{Q}^{2}$ predictive relevance indicator procedure uses a block of $N$ cases and $M$ indicators and takes out a part of the $N$ by $M$ data points. The estimation is conducted by using the omission distance $d$ in which every $d$ data point is excluded and calculated separately. This continues until the procedure reaches the end of the data matrix (cf. Wold 1982; Chin 1998).

The predictive relevance indicator is represented by:

$$
\mathrm{Q}^{2}=1-\frac{\sum_{\mathrm{d}} \mathrm{SSE}_{\mathrm{d}}}{\sum_{\mathrm{d}} \mathrm{SSO}_{\mathrm{d}}}
$$

where $\mathrm{Q}^{2}$ represents a fit between observed values and values reconstructed by the model. The sum of squares of prediction errors (SSE) represents the estimated values after the data points were omitted. The sum of squares of observations (SSO) represents the mean value for prediction. $\mathrm{Q}^{2}$ values above zero $\left(\mathrm{Q}^{2}>0\right)$ indicate that observed values are well reconstructed and a model has predictive relevance; $\mathrm{Q}^{2}$ values below zero $\left(Q^{2}<0\right)$ indicate that observed values are poorly reconstructed and that the model has no predictive relevance (Fornell \& Bookstein 1982; Chin 1998; Henseler et al. 2009). The relative impact of the predictive relevance can be assessed by the $\mathrm{q}^{2}$ indicator. This measure can be calculated:

$$
q^{2}=\left(\mathrm{Q}^{2} / 1-\mathrm{Q}^{2}\right)
$$

where $\mathrm{Q}^{2}$ represents the above-presented predictive relevance. The assessed variables of the model reveal a small impact of the predictive relevance if $\mathrm{q}^{2} \leq .02$, a medium impact of the predictive relevance if $\mathrm{q}^{2}$ has a value between .02 and .15; and a strong impact of the predictive relevance if $\mathrm{q}^{2} \geq .35$. Interested readers are referred to Wold (1982), Fornell and Bookstein (1982) and Chin (1998b) for further discussion.

The average variance extracted $\rho_{\eta}$ for the construct can be calculated as (Fornell \& Larcker 1981):

$$
\rho_{\eta}=\frac{\sum \lambda_{\mathrm{yi}}^{2}}{\sum \lambda_{\mathrm{yi}}^{2}+\sum \operatorname{Var}\left(\varepsilon_{\mathrm{i}}\right)}
$$

where $\lambda_{\mathrm{i}}$ is the component loading to an indicator and $\operatorname{Var}\left(\varepsilon_{\mathrm{i}}\right)=1-\lambda_{\mathrm{i}}^{2}$. If the average variance extracted $\rho_{\eta}$ is bigger than 0.50 , the variance due to measurement error is smaller than the variance captured by the construct $\eta$, and validity of the individual indicator $\left(\mathrm{y}_{\mathrm{i}}\right)$ and construct $(\eta)$ is well-established (Fornell \& Larcker 1981).

Goodness-of-fit in CBSEM: Measures of absolute fit, incremental fit and model parsimony in detail

Table B.1 represents measures of absolute fit, incremental fit and model parsimony in detail. For detailed technical assessment and explanations, interested readers are referred to Marsh and Hau (1996), $\mathrm{Hu}$ and Bentler (1999); Kenny and McCoach 2003 and Hair et al. (2010).

Table B.1: Measures of absolute fit, incremental fit and model parsimony

\begin{tabular}{l|l|l}
\hline Topic & Measure & Preferred value \\
\hline \multirow{5}{*}{$\begin{array}{l}\text { Overall fit } \\
\text { measures }\end{array}$} & Chi-square $\left(\chi^{2}\right)$ & $0.05 \geq \mathrm{p} \leq 0.20$ \\
\cline { 2 - 3 } & degrees of freedom (df) & $\begin{array}{l}\text { no p.v., the researcher uses for } \\
\text { comparative and computational purposes }\end{array}$ \\
\cline { 2 - 3 } & Chi-square / df ratio & $<2.0$ \\
\cline { 2 - 3 } & Goodness-of-fit index (GFI) & $\geq 0.90$ \\
\cline { 2 - 3 } & Root mean square residual (RMSR) & $\leq 0.08$ \\
\cline { 2 - 3 } & $\begin{array}{l}\text { Root mean square error of approximation } \\
\text { (RMSEA) }\end{array}$ & no threshold level, practice suggest $\leq 0.08$ \\
\cline { 2 - 3 } fit measures & Confidence interval of RMSEA & $\begin{array}{l}0.0-1.0, \text { larger values indicate higher } \\
\text { levels of G-of-F }\end{array}$ \\
\cline { 2 - 3 } & Comparative fit index (CFI) & $\begin{array}{l}0.0-1.0, \text { larger values indicate higher } \\
\text { levels of G-of-F }\end{array}$ \\
\cline { 2 - 3 } & Incremental fit index (IFI) & $\geq 0.90$ \\
\cline { 2 - 3 } & Tucker - Lewis index (TLI / NNFI) & \\
\hline
\end{tabular}




\begin{tabular}{l|l|l}
\hline \multirow{4}{*}{\begin{tabular}{l|l} 
Model \\
parsimony
\end{tabular}} & Relative non-centrality index (RNI) & $\geq 0.90$ \\
\cline { 2 - 3 } & Relative fit index (RFI) & $\geq 0.90$ \\
\cline { 2 - 3 } & Normed fit index (NFI) & $\geq 0.90$ \\
\cline { 2 - 3 } & Adjusted goodness-of-fit index (AGFI) & $\geq 0.90$ \\
\cline { 2 - 3 } & Parsimony normed fit index (PNFI) & Higher value, better fit \\
\hline
\end{tabular}

Overall (absolute) fit measures (indices). The researcher can apply several overall fit measures, such as likelihood-ratio chi statistics, degrees of freedom, GFI, AGFI, RMSR, RMSEA, etc. The only statistically based measure of goodness-of-fit in the CBSEM application is the likelihood-ratio chi-squared $\left(\chi^{2}\right)$ statistic. According to Fornell and Larcker (1981), the $\chi^{2}$ statistic compares the fit between the covariance matrices for the observed data and theoretically created model. The researcher investigates the non-significant difference between the actual and predicted matrices (cf. Hair et al. 2010; Gatignon 2003), because the theoretical model strives to account for all the covariance among the latent constructs. In other words, we are looking for the nonsignificant $\chi^{2}$, which is opposite to common statistical logic where the researcher is striving to obtain a model that is statistically significant at a certain level, usually at 1 or $5 \%$. Indications that actual and predicted input covariance matrices are not statistically different might be obtained if the $\chi^{2}$ value is $0.05 \geq p \leq 0.20$ (Hair et al. 2010; Marsh \& Hau 1996; cf. Bagozzi \& Phillips 1982). Some recent studies (e.g. Marsh et al. 2004) have suggested that $\chi^{2}$ should be used for statistical testing of a model fit, rather than for descriptive use of a model fit assessment.

The degrees of freedom (df) of an estimate are the amount of independent pieces of information available to estimate a model, i.e. the number of parameters that are free to vary in a model. The fundamental difference between SEM and other statistical techniques is in fact that $d f$ in the SEM application is based on the size of the covariance matrix (Hair et al. 2010), which is based on the number of indicators, and not on the sample size.

The goodness-of-fit index (GFI) is a nonstatistical index that measures the overall degree of model fit. The fit ranges from very poor
(GFI=0.0) to perfect $(\mathrm{GFI}=1.0)$. The adjusted goodness-of-fit index (AGFI) differs from the GFI in terms of its adjustment for the number of degrees of freedom in the model (Byrne 1998). These two indices can be understood as absolute indices of fit because they compare the hypothesized model with no model at all (Byrne 1998) as well as an index of parsimony for the overstated parameter number and relationships. Hair et al. (2010) have advocated that higher values indicate better fit, which in practical application is accepted as $\geq 0.90$ even though there is no established minimum acceptability level.

The root mean square residual (RMSR) represents the average of the residual's fit between observed and estimated input matrices (Hair et al. 2010; Byrne 1998). For this index there does not exist an official threshold level (Hair et al. 2010), but in the literature (Byrne 1998) and practice for the standard RMSR $\leq 0.08$ is established.

The root mean square error of approximation (RMSEA) is a measure that estimates how well the population non-centrality index $\Phi$ (Steiger 1990) fits to a population covariance matrix per degrees of freedom (cf. Baumgartner \& Homburg 1996) and controls the $\chi^{2}$ statistics to reject models with a large sample or a large number of variables (cf. Hair et al. 2010). The purpose of the RMSEA in an SEM study is to adjust the complexity of the model and sample size. Theory does not advise as to a generally acceptable threshold value, but in practice the RMSEA $\leq 0.08$ is established. The researcher should take into consideration the level of the confidence interval.

Comparative (incremental) fit measures. A great number of incremental fit measures that exist in the literature, and that are mostly used in practical CBSEM applications, are: normed fit 
index (NFI), comparative fit index (CFI), incremental fit index (IFI) and Tucker-Lewis index (TLI). The normed fit index (Bentler and Bonett 1980) represents a relative comparison between a proposed and the null model (Hair et al. 2010). The fit ranges from very poor (NFI $=0.0)$ to perfect $(\mathrm{NFI}=1.0)$, with preferred value $\geq 0.90$. This index was a "classic" criterion of model choice in the 1980s, until it became evident that the NFI underestimated the model fit in small samples (Byrne 1998). Bentler (1990) revised the normed fit index and proposed the comparative fit index (Byrne 1998). The index value has a range of $0.0-1.0$, where larger values indicate higher levels of goodness-of-fit. The Tucker-Lewis index (1973), also known as the non-normed fit index (NNFI), represents a measure of parsimony between the comparative index in the proposed and null models (Marsh \& Hau 1996; Hair et al. 2010). The TLI estimates a model fit per degree of freedom, penalizing less parsimonious models (Baumgartner \& Homburg 1996). A recommended value is $\geq 0.90$. The incremental fit index (Bollen 1989a) describes the parsimony of the sample size in the estimated and null model. The values lie between 0.0-1.0, and larger values indicate higher levels of goodness-of-fit.

Model parsimony. Parsimony of the SEM model represents comparisons among competing models, in which the researcher compares observed model fit relative to its complexity. A parsimony fit is estimated as the ratio of degrees of freedom (df) with reference to the total degrees of freedom $\left(\mathrm{df}_{\mathrm{t}}\right)$ available for the estimation (Marsh \& Hau 1996). Parsimony ratio is represented by coefficient $\psi$ :

$$
\psi=\mathrm{df}_{\mathrm{o}} / \mathrm{df}_{\mathrm{t}}
$$

This equation states that the greater the observed degrees of freedom $\left(\mathrm{df}_{\mathrm{o}}\right)$ are, the greater the parsimony ratio will be, which indicates the better fit of the model (cf. Marsh \& Hau 1996; Kenny \& McCoach 2003; Hair et al. 2010). Parsimony fit indices, such as the adjusted goodness-of-fit index (AGFI) and parsimony normed fit index (PNFI), tend to relate model fit to model complexity, which is similar to the application of an adjusted $\mathrm{R}^{2}$ (Hair et al. 2010). The PNFI is used as an adjustment of the normed fit index (NFI). Higher values represent better fit and model adjustment. The researcher is advised not to use these indices in a single model as an independent measure, but rather as a tool to compare the fit of competing models.

Competitive fit - Nested models. The primary goal of an SEM study is to show acceptable model fit, employing numerous goodness-of-fit indices, as well as to confirm that the tested model has no better theoretical alternative. Assessment of the competing models, which must be grounded in theory, can be conducted by comparison using incremental and parsimony fit measures as well as with differences in the likelihood-ratio chisquared statistics. The researcher can compare models of similar complexity, but with variation in terms of the underlying theoretical relationships (Hair et al. 2010; Schreiber et al. 2006; cf. Anderson \& Gerbing 1982). If a model contains the same number of latent constructs as a competing model, and alters the paths and causality among them, the researcher can compare nested models by examining the difference in chisquared statistics $\left(\Delta \chi^{2}\right)$. 